\title{
Supplement to this Special Issue of The Caring Campus Project
}




\section{Movember Caring Campus Toolkit}

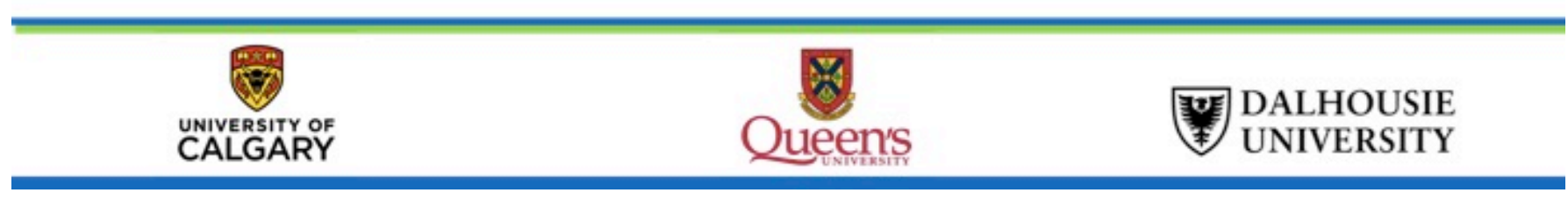




\section{Acknowledgement}

This Toolkit represents the work of the three-year Movember, Canada funded project, the Caring Campus Project, which addressed substance misuse and associated mental health issues on Canadian campuses, focusing particularly on the health and well-being of firstyear men.

The Caring Campus Project involved the following researchers, research teams, and student initiatives from three Canadian university campuses:

\section{Queen's University}

Dr. Shu-Ping Chen

Dr. Terry Krupa

Dr. Heather Stuart

Josh Decaire

George Konstantinidis

Michelle Koller

Dr. Salinda Horgan

Tiina Liinamaa

Student initiative:

Queen's for the Boys

(http://www.queensftb.com)
University of Calgary

Dr. Keith Dobson

Laura Henderson

Liza Mastikhina

Student initiative:

Man Up for Mental Health

(http://www.manupyyc.com)

\section{Dalhousie University}

Dr. Sherry Stewart

Dr. Michael Teehan

Dr. Kara Thompson

Craig Moore

Dr. Amanda Hudson

Jennifer Swansburg

Parnell DavisMacNevin

Annie Chinneck

Meredith Ivany

Student initiative: ProSocial

Project

(http://theprosocialproject.ca) 


\section{Table of Contents}

Module One: Overview of the Caring Campus Project.............................................6

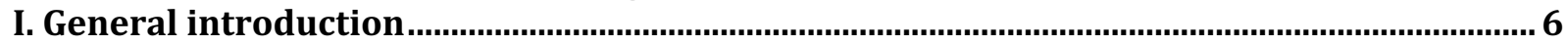

II. Purpose of this toolkit ............................................................................................................ 6

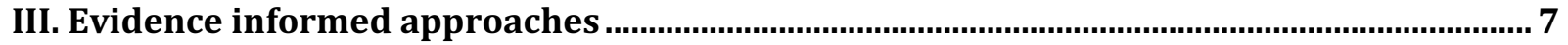

IV. Caring Campus Project: Philosophy and Principles of Change....……………………………8

Module Two: Substance Use Wellness Tool......................................................... 10

I. Background ...........................................................................................................................10

II. The Substance Use Wellness Tool .................................................................................11

III. Dissemination of the Substance Use Wellness Tool ............................................................12

1. Strategic distribution of the Substance Use Wellness Tool............................................................. 12

2. Development of student workshops engaging students in the use of the Substance Use

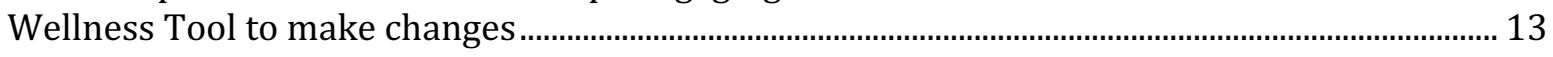

Module Three: The Summit Approach................................................................... 15

I. Student engagement and empowerment: Theory and principle ........................................15

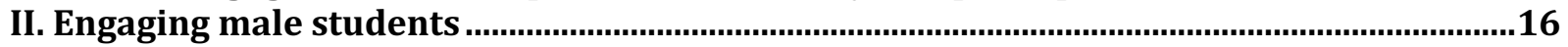

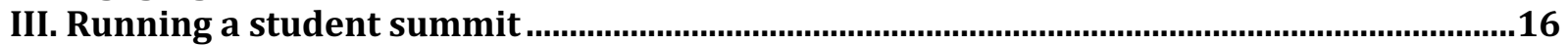

1. Recruitment and advertising................................................................................................... 16

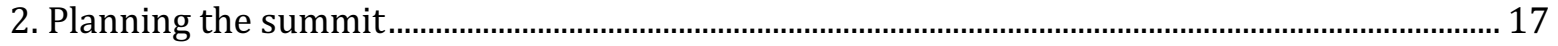

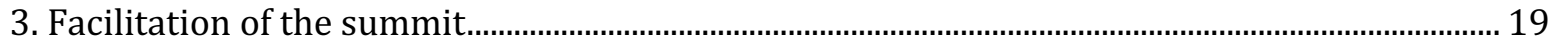

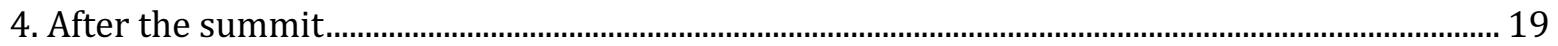

IV. Branding and challenging masculinity ................................................................................20

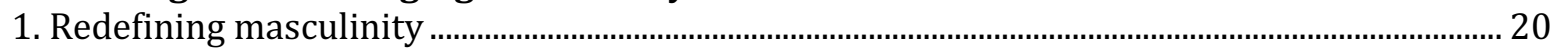

2. Capitalising on a known brand ……………………………………………………………………..... 21

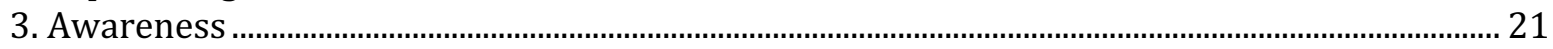

V. Challenges and tensions...........................................................................................22

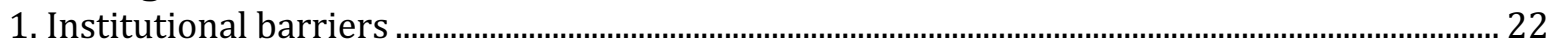

2. Partnering with other programs/clubs/initiatives......................................................................... 23

3. Concerns over "men's groups" on campus .............................................................................................. 24

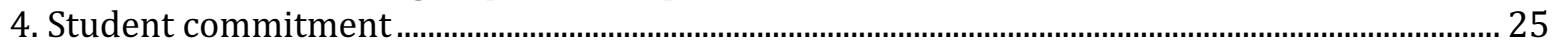

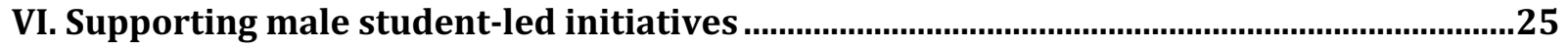

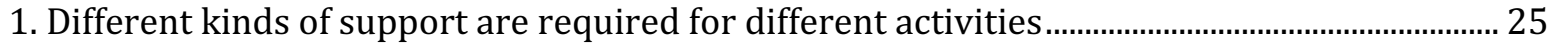

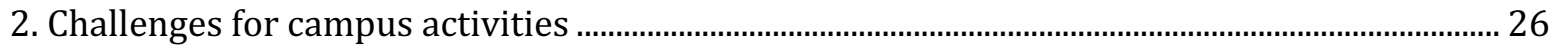

Module Four: Social Norms Messaging ............................................................... 27

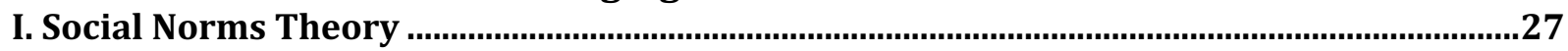

II. Social Norms Messaging...............................................................................................2

1. How to Design a Social Norms Messaging Campaign:......................................................................... 28

III. Challenges in Developing A Social Norms Messaging Campaign:........................................30

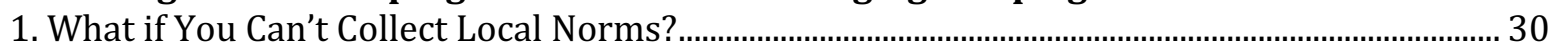

2. What if There is No Healthy Norm to Report or if Perceptions are Correct?................................ 30

IV. Summary.............................................................................................................................32

Module Five: Contact-based Education .................................................................. 33

I. Contact-based education: Theories and principles .................................................................33

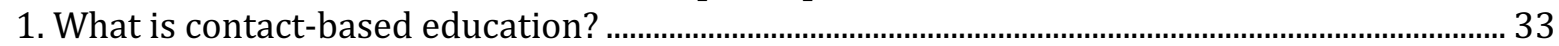

2. How has contact-based education been applied and what is the evidence supporting its use? 
3. What are the potential benefits of contact-based education applied to substance misuse on postsecondary campuses?

II. Designing and implementing contact-based education focused on substance misuse on

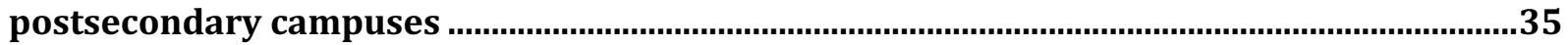

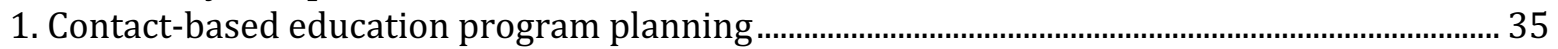

2. Speaker recruitment, training, and support.................................................................................. 36

3. Building a supported and engaged team of CBE speakers ............................................................ 37

4. Developing and delivering personal stories ........................................................................................ 38

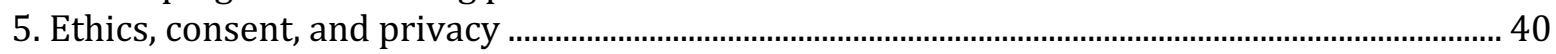

III. Disseminating, evaluating, and sustaining contact-based education ..................................41

Module Six: Program Sustainability ................................................................... 42

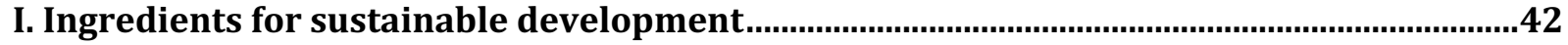

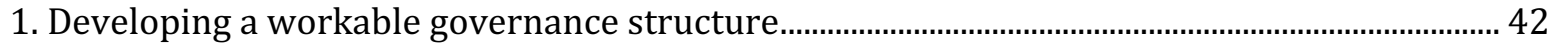

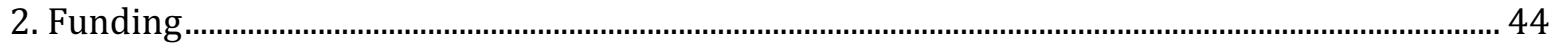

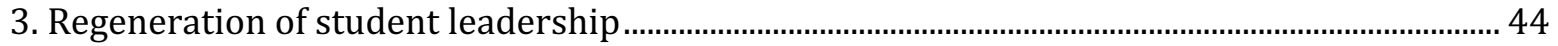

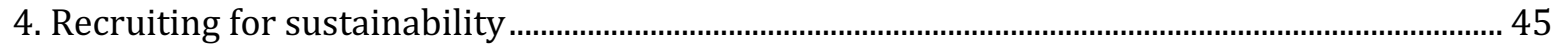

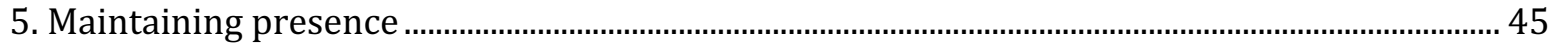

II. Summary

References \& Resources ......................................................................................... 47

Appendix A1: The Substance Use Wellness Tool - Leaflet.................................... 50

Appendix A2: The Substance Use Wellness Tool - Information package........... 51

Appendix A3: PowerPoint slides from one workshop related to the Substance Use

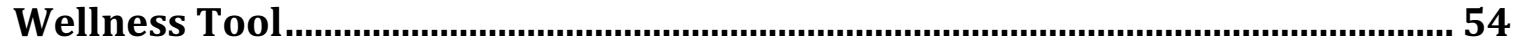

Appendix B: The Summit Approach - Example of Job posting to hire student leaders

Appendix C. Contact-based Education - Speaker Training Package .................. 61 


\section{Module One: Overview of the Caring Campus Project}

\section{General introduction}

Substance use and misuse has become part of the post-secondary university experience in Canada and elsewhere. Misuse of substances, particularly alcohol, is especially pronounced among male students. Canadian research shows that twice as many young men aged 20-24 years report heavy and frequent drinking compared to females in the same age group (Health Canada, 2008). First year male university students are at particularly high risk for alcohol misuse as they grapple with their newfound independence.

Mental ill health is closely associated with substance misuse, both as a risk factor and as a consequence. While there has been increasing interest in the mental health of students on post-secondary campuses alcohol misuse has generally received less attention. Healthy Minds, Health Campuses in British Columbia (https://healthycampuses.ca/) is an example of an initiative focused on rectifying this situation by building capacity on campuses to promote mental wellness and healthy relationships with substances. Any discussion related to the mental health of young people on post-secondary campuses must include attention to harmful patterns of alcohol use; the Caring Campus Project was developed with this in mind.

The Caring Campus Project was funded by Movember Canada. This three-year project focused on reducing substance misuse in first year male post-secondary students to promote mental health and well-being. There was a particular focus on alcohol misuse. The project brought male student leaders together to learn about substance use and its connection to mental health, to encourage them to raise awareness among their peers, and to enable them to create sustainable cultural change within their campus communities to reduce harmful patterns of substance use. This is a student centred and student led initiative that engages young men at every level of the campus. The project unfolded at three Canadian universities: first Queen's University, and then University of Calgary, and Dalhousie University.

\section{Purpose of this toolkit}

This toolkit is designed to assist other post-secondary institutions in addressing substance misuse and mental health problems on their campuses using the Caring Campus model. Although this model has been tested in three university campuses and was designed to target first year men it likely has broader applicability. For example, it is likely that the issues and approaches have relevance across both university and community college 
contexts. As well, some of the approaches used may be fruitfully adapted for use with other populations such as university men and women across all years (not just first year men), and high school youth.

\section{Evidence informed approaches}

The Caring Campus Project applies three evidence informed approaches to positively influence substance misuse patterns of first year male university students:

1. The Substance Use Wellness Tool adapted the Mental Health Continuum Model developed for use in Canada's Department of National Defense (2016) to create a continuum of substance use patterns from low risk, moderate risk, and higher risk. It allows students to place themselves on the continuum of risk based on specific behavioural cues and consequences and to monitor their substance use behaviours and those of their peers.

2. Contact-based education provides opportunities for students who have experience with substance use problems to share - directly and through video clips - their actual experiences with this issue. The students describe the problems that substance misuse has caused them, how they dealt with their substance misuse, and how they came to experience well-being. In the mental health field, such stories have been found to bridge the gap between awareness and action for students in the audience who might have a similar problem. When the messages delivered in these presentations include hope, acceptance, and the need for early identification and intervention, students who are experiencing mental health problems are more likely to respond.

3. Student Summits bring together students to act as leaders on campus to learn about substance misuse and mental health issues, the availability of local resources, as well as the experiences of peers who have faced substance abuse problems. Student leaders then consider ways in which they can create sustainable cultural change within their campus communities and take leadership to initiate awareness and anti-stigma activities throughout the course of the school year. Their activities echo the messages delivered through the contact-based interventions and work to create sustainable cultural change. When applied in the mental health field, the critical ingredients of change for this approach include youth-driven activities and culturalsensitivity. 


\section{Caring Campus Project: Philosophy and Principles of Change}

The Caring Campus Project model uses a community empowerment philosophy to support young male students to explore how the campus culture and masculine ideals may promote substance misuse, and to consider how substance misuse can undermine their mental health. It recognises a culture of 'maleness' with shared beliefs, knowledge, attitudes, social actions, language, and interactions with others.

First and foremost, this approach understands change as occurring at the level of the community, particularly the community of men, thorough a process of community mobilization including:

- Identification of problems requiring change

- Dialogue and deliberation as a collective to name the problem and seek solutions

- Ownership of the problem and investment in the processes that leads to health and well-being

- Self-governance to support action

- Action by the collective

Second the approach requires consideration of features of the specific contexts within which the intervention is to be applied. Although there are shared characteristics across post-secondary campuses, each campus will have features specific to the context. For example, substance use patterns will be influenced by the extent to which the campus population is living away from home in student residences or other student accommodations.

Third, the approach supports partnership synergy where the community mobilises and connects with other stakeholders and groups to support collective activity to reach shared goals.

Fourth, the approach promotes the development of tools with and for the community to be used to raise awareness of the problems associated with alcohol and other substance misuse.

Fifth, the approach creates multiple avenues of involvement to support community mobilisation including empowerment of student leaders, participatory research, and tool development.

Sixth, the approach creates non-stigmatizing ways to open and sustain meaningful dialogue about issues of substance misuse and mental health. 
Seventh, the approach relies on a systematic collection of qualitative and quantitative data to identify the nature, scope, and prevalence of the problem and to engage students to identify with the problem and use the data and data collection processes to connect to their own solutions and messages. Change is considered from multiple perspectives and includes short-term, intermediate and long-term changes. It acknowledges that the contribution of these efforts need to be considered in relation to the influence of other related initiatives on campus.

Eighth, the approach mobilizes sustainable community action and may operate outside of existing organisational structures.

Ninth, the approach recognizes that there are community and organizational readiness factors that may support or hinder activities, such as the capacity for engaging in genderoriented discussions, the ability to support student empowerment, and the extent to which disquieting or uncomfortable messages may be openly discussed and acted upon.

For a more comprehensive overview of the Caring Campus Project see the first article in this special issue of the Canadian Journal of Community Mental Health: The Caring Campus Project Overview which begins on page 1.

Stuart, H., Chen, SP, Krupa, T., Narain, T., Horgan, S., Dobson, K. and Stewart, S. (2018) The Caring Campus Project Overview. Canadian Journal of Community Mental Health, 1. 


\section{Module Two: Substance Use Wellness Tool}

\section{Background}

The Substance Use Wellness Tool describes substance use patterns of post-secondary students substance according to the degree of disruption in their daily lives across a range of dimensions. The Substance Use Wellness Tool was modeled on the Mental Health Continuum Model developed by the Canadian Department of National Defense (2016) and is used by the Mental Health Commission of Canada (Stuart, et. al, 2014a; Stuart, et. al., 2014b) The Mental Health Continuum Model uses a colour spectrum without medical terminology to normalise mental health conditions, promote dialogue, and encourage help seeking. Soldiers living with mental health problems often speak about being "yellow" or "orange" when they are having difficulties and are seeking help from their informal and formal support networks. The colour spectrum has provided a new and destigmatizing language that can be used to communicate mental health risks.

The Substance Use Wellness Tool presents a matrix of 13 domains with specific behavioural indicators according to the level of disruption in the daily life of postsecondary students - from no problems (green), to mild concerns (yellow), moderate disruptions (orange), and severe disruptions (red) (Figure 2-1). The Tool was developed and is applied in a non-judgemental manner, recognizing that students can experience benefits from substance use and that understanding the negative aspects and consequences of substance use requires consideration of multiple factors.

Students can use self-reflection to place themselves on the continuum of risk, based on the characteristics and behavioural indicators described in each domain of the tool. The columns (green, yellow, orange, or red) suggest the degree of risk associated with any specific dimension, as well as larger patterns of risks associated with multiple dimensions. In this way, a student can self-monitor alcohol or drug use and their impact on daily life. The use of the Substance Use Wellness Tool is only the first step. Students can use this information to determine their need for supports, whether informal supports (such as family or friends) or, where patterns of use fall in the orange and red columns, the formal supports offered on campus or broader community resources. The tool also provides a way for students to care for their peers by attending to their substance use with a view to supporting healthy patterns of substance use, watching out for their well-being, offering support and encouraging access to formal supports as required. 
The tool was developed through a series of focus groups held with students and others to understand how they experience substance misuse as it is enacted in the campus context. From these focus group conversations, the dimensions and indicators emerged. The development of the tool was followed by validation research.

For more information about the development and validation of this tool, please see the following article in this special issue of the Canadian Journal of Community Mental Health:

Chen, SP, Stuart, H. Krupa, T., Dobson, K. and Stewart, S. (2018). The Development and Psychometric Testing of a Substance Use Wellness Tool. Canadian Journal of Community Mental Health, 15.

\section{The Substance Use Wellness Tool}

Each column in the Substance Use Wellness Tool (Figure 2-1) incorporates a functional matrix of 13 domains with specific behavioural indicators relating to the colours green, yellow, orange, and red featured in the top row.

- Domain 1 Control ranges from no/limited substance use to a persistent desire and unable to control use; describes level of difficulty with control of substance use.

- Domain 2 Amount and Frequency ranges from no substance use, excessive use, to persistent use of excessive amounts; describes the amount and frequency of a student's substance use.

- Domain 3 Coping describes the degree to which a student uses substances as a coping strategy to manage stress or negative emotions.

- Domain 4 Social - Peer pressure ranges from never/rarely to almost always; describes the degree to which a student uses substances in social situations as a response to peer pressure.

- Domain 5 Pattern of use, ranges from never/rarely to almost always; describes the frequency that a student uses substances alone.

- Domain 6 Social - Peer use ranges from don't use to frequently use; describes the degree to which peers use substances.

- Domain 7 Motivation ranges from never to almost always; describes the frequency to which students use substances to get high.

- Domain 8 Relationship ranges from no to almost always; describes the degree to which students' connections are affected by substance use and those connects expressed concerns about students' substance use. 
- Domain 9 Activity ranges from no to almost always; describes the degree to which a student's social, occupational, and recreational activities are dominated by of substance use.

- Domain 10 Academic Performance ranges from not impacted to failing to meet educational goals; describes the degree to which a student's academic performance is impacted by substance use.

- Domain 11 Physical ranges from never felt unwell to poor physical well-being; describes the degree of physical illness due to substance use.

- Domain 12 Financial ranges from not impacted to having significant financial trouble; describes the degree of a student's financial status impacted by substance use.

- Domain 13 Behavioural ranges from never to almost always; describes the frequency that students engage in behaviours resulting in harm to self or others due to substance use.

\section{Dissemination of the Substance Use Wellness Tool}

The Substance Use Wellness Tool was developed to raise awareness of the intersection between substance use and various aspects of everyday living. We implemented several approaches to disseminate the tool.

\section{Strategic distribution of the Substance Use Wellness Tool}

We created a leaflet (Appendix A1) containing the Substance Use Wellness Tool and a description of its purpose, which was distributed in campus kits and provided to student wellness services to be incorporated into a drinking awareness campaign. Examples of distribution included:

- Orientation kits

- Handouts at the Library

- Engineering Wellness Event Bags

- Distribution to faculty counsellors

- Incorporated in wellness services and their workshops

- Residence bulletin boards and resident don handouts

- The Caring Campus Student leader run events

- Special health and wellness events across campus 
We developed partnerships to incorporate the Substance Use Wellness Tool into various mental health organisations' initiatives on campus to ensure its sustainability and widespread dissemination. For example, this included:

- An information package (Appendix A2) explaining what the Substance Use Wellness Tool colour continuum is, and how to use it for distribution by student health services

- A brief training package developed to incorporate the Substance Use Wellness Tool colour continuum in student residences, orientation, leadership and peer support training;

- Engagement of stakeholders to include the Substance Use Wellness Tool as an educational resource in faculty orientation, student handbooks, etc.

\section{Development of student workshops to engage students in the use of the Substance Use Wellness Tool to make changes}

To help students move from awareness to action, we developed brief workshops to teach them how to use the Substance Use Wellness Tool and to engage students in applying the tool to their specific circumstances. For example, a workshop with student athletes embedded three major components of the Substance Use Wellness Tool:

- Reflection: Student athletes were guided to identify their substance use patterns using the Substance Use Wellness Tool (e.g., where are you are in the continuum?; what do you note about your patterns?). Then the students reflected as a group on their substance use patterns and the impact these patterns had on their daily lives.

- $\quad$ Personalisation: Students were guided to interpret the Substance Use Wellness Tool colour continuum in their personal context (e.g., specific to the athletic context) and discussed dimensions particularly relevant to their situation. For example, student athletes noted that the end of an athletic season tended to be a time for heavy drinking and noted the strong connections being made in their social circles made between celebrations of athletic achievement and heavy alcohol use.

- Action: Students were empowered to think and plan for one thing they could do to make a change in their situation. For example, students discussed potential alternative activities to drinking to mark important athletic achievements. In addition, workshops could include knowledge and practice of specific coping strategies. For example, the link between the pressures of student life and substance use was highlighted by students in the development of the substance use wellness tool and so workshops included knowledge and practice of mindfulness to manage stress. 


\section{The PowerPoint slides from one of these workshops is available in the appendix of this Toolkit (Appendix A3).}

\begin{tabular}{|c|c|c|c|c|}
\hline Control & $\begin{array}{l}\text { No or limited use of } \\
\text { substances }\end{array}$ & $\begin{array}{l}\text { Regular but controlled use of } \\
\text { substances }\end{array}$ & $\begin{array}{l}\text { Increased use of substances and } \\
\text { difficulty with control }\end{array}$ & $\begin{array}{l}\text { A persistent desire for substance and } \\
\text { unable to control use of substances }\end{array}$ \\
\hline $\begin{array}{l}\text { Amount/ } \\
\text { frequency }\end{array}$ & $\begin{array}{l}\text { No excessive use of } \\
\text { substances }\end{array}$ & $\begin{array}{l}\text { Excessive use of substances once or } \\
\text { twice a week }\end{array}$ & $\begin{array}{l}\text { Consistent excessive use of } \\
\text { substances more than two times a } \\
\text { week }\end{array}$ & $\begin{array}{l}\text { Persistently use excessive amounts of } \\
\text { substances }\end{array}$ \\
\hline Coping & $\begin{array}{l}\text { Do not use substances as a } \\
\text { coping strategy to manage } \\
\text { stresses or negative emotions }\end{array}$ & $\begin{array}{l}\text { Sometimes use substances as a } \\
\text { coping strategy to manage stresses } \\
\text { or negative emotions }\end{array}$ & $\begin{array}{l}\text { Often use substances as a coping } \\
\text { strategy to manage stresses or } \\
\text { negative emotions }\end{array}$ & $\begin{array}{l}\text { Use substances as the main coping } \\
\text { strategy to manage stresses or } \\
\text { negative emotions }\end{array}$ \\
\hline $\begin{array}{l}\text { Social- peer } \\
\text { pressure }\end{array}$ & $\begin{array}{l}\text { Never or rarely use } \\
\text { substances in social } \\
\text { situations as a response to } \\
\text { peer pressure }\end{array}$ & $\begin{array}{l}\text { Sometimes use substances in social } \\
\text { situations as a response to peer } \\
\text { pressure }\end{array}$ & $\begin{array}{l}\text { Often use substances in social } \\
\text { situations as a response to peer } \\
\text { pressure }\end{array}$ & $\begin{array}{l}\text { Almost always use substances in } \\
\text { social situations as a response to peer } \\
\text { pressure }\end{array}$ \\
\hline $\begin{array}{l}\text { Pattern of } \\
\text { use }\end{array}$ & Rarely uses substances alone & Sometimes uses substances alone & Often use substances alone & $\begin{array}{l}\text { Almost always use substances in } \\
\text { isolation }\end{array}$ \\
\hline $\begin{array}{l}\text { Social-peer } \\
\text { use }\end{array}$ & $\begin{array}{l}\text { Peers don't or only } \\
\text { occasionally use substances }\end{array}$ & Peers sometimes use substances & $\begin{array}{l}\text { Peers often focus much of their } \\
\text { activities on substance use }\end{array}$ & $\begin{array}{l}\text { Peers almost always focus their } \\
\text { activities on substance use }\end{array}$ \\
\hline Motivation & $\begin{array}{l}\text { Never use substance to get } \\
\text { high }\end{array}$ & $\begin{array}{l}\text { Sometimes use substances to get } \\
\text { high }\end{array}$ & Often use substances to get high & $\begin{array}{l}\text { Almost always use substances to get } \\
\text { high }\end{array}$ \\
\hline $\begin{array}{l}\text { Relation- } \\
\text { ship }\end{array}$ & $\begin{array}{l}\text { Connections are not affected } \\
\text { by substance use; they } \\
\text { expressed no concerns about } \\
\text { my substance use }\end{array}$ & $\begin{array}{l}\text { Connections are sometimes affected } \\
\text { by substance use; they have } \\
\text { expressed some concerns about my } \\
\text { substance use }\end{array}$ & $\begin{array}{l}\text { Connections are often affected by } \\
\text { substance use; they have expressed } \\
\text { moderate concerns about my } \\
\text { substance use }\end{array}$ & $\begin{array}{l}\text { Connections are almost always } \\
\text { affected by substance use; they have } \\
\text { expressed serious concerns about my } \\
\text { substance use }\end{array}$ \\
\hline Activity & $\begin{array}{l}\text { Social, occupational, or } \\
\text { recreational activities are not } \\
\text { sacrificed because of } \\
\text { substance use }\end{array}$ & $\begin{array}{l}\text { Social, occupational, or recreational } \\
\text { activities are sometimes replaced } \\
\text { by substance-related activities }\end{array}$ & $\begin{array}{l}\text { Social, occupational, or recreational } \\
\text { activities are often dominated by } \\
\text { substance-related activities }\end{array}$ & $\begin{array}{l}\text { Social, occupational, or recreational } \\
\text { activities are almost always } \\
\text { dominated by substance-related } \\
\text { activities }\end{array}$ \\
\hline $\begin{array}{l}\text { Academic } \\
\text { performance }\end{array}$ & $\begin{array}{l}\text { Academic performance is not } \\
\text { impacted by substance use }\end{array}$ & $\begin{array}{l}\text { Due to substance use, sometimes } \\
\text { miss classes or deadlines; } \\
\text { educational goals not in jeopardy }\end{array}$ & $\begin{array}{l}\text { Due to substance use, often miss } \\
\text { classes or deadlines; jeopardizing } \\
\text { educational goals and GPA }\end{array}$ & $\begin{array}{l}\text { Due to substance use, failing to meet } \\
\text { educational goals }\end{array}$ \\
\hline Physical & $\begin{array}{l}\text { Never felt physically unwell } \\
\text { due to substance use }\end{array}$ & $\begin{array}{l}\text { Sometimes feel physically unwell } \\
\text { due to substance use }\end{array}$ & $\begin{array}{l}\text { Often feel physically unwell due to } \\
\text { substance use }\end{array}$ & $\begin{array}{l}\text { Recurrent substance use results in } \\
\text { poor physical well-being }\end{array}$ \\
\hline Financial & $\begin{array}{l}\text { Finances are not impacted by } \\
\text { substance use }\end{array}$ & $\begin{array}{l}\text { Finances are occasionally impacted } \\
\text { by substance use }\end{array}$ & $\begin{array}{l}\text { Finances are often impacted by } \\
\text { substance use }\end{array}$ & $\begin{array}{l}\text { Have significant financial troubles } \\
\text { (spend most money on substances) }\end{array}$ \\
\hline \multirow[t]{2}{*}{ Behavioural } & $\begin{array}{l}\text { Never engage in behaviours } \\
\text { resulting in harm to self or } \\
\text { others due to substance use }\end{array}$ & $\begin{array}{l}\text { Sometimes engage in behaviours } \\
\text { resulting in harm to self or others } \\
\text { due to substance use }\end{array}$ & $\begin{array}{l}\text { Often engage in behaviours } \\
\text { resulting in harm to self or others } \\
\text { due to substance use }\end{array}$ & $\begin{array}{l}\text { Almost always engage in behaviours } \\
\text { resulting in harm to self or others due } \\
\text { to substance use }\end{array}$ \\
\hline & GOOD & $\begin{array}{l}\text { CAUTION } \\
\text { Recognize your substance-related } \\
\text { issues, seek support }\end{array}$ & $\begin{array}{l}\text { ALERT } \\
\text { Talk to someone, seek professional } \\
\text { helps, make self-care a priority. } \\
\text { Don't withdraw. }\end{array}$ & $\begin{array}{r}\text { ALARM } \\
\text { Seek professional helps }\end{array}$ \\
\hline
\end{tabular}

Figure 2-1. The Substance Use Wellness Tool 


\section{Module Three: The Summit Approach}

\section{Student engagement and empowerment: Theory and principle}

There is a positive association between student engagement and overall academic success; however, motivating students to engage in co-curricular activities can be a challenge. Even where students have interest and motivation to participate, student time is a critical and finite resource and students are likely to invest time only when they feel they are gaining something.

Having, or the perception of having, a leadership role, and having a sense of autonomy in roles has been shown to motivate youth involvement with noncurricular activities (Hansen \& Larson, 2007; Ahlfeldt, Mehta, \& Sellnow, 2005). Connection represents another critical motivator for getting students to engage in co-curricular activities; students who feel a strong sense of belonging are much more likely to get involved (Juvonen, Espinoza, \& Knifsend, 2012). Additionally, if the activity results in students interacting with their peers cooperatively, students are more likely to continue their participation (Holloway, 2002).

The Caring Campus Project incorporated these elements by ensuring that initiatives, events, and campaigns were largely student led. Staff working on the Caring Campus Project played a role in supporting and assisting with the execution of plans, but the inspiration centred around what the students want to see developed on their own campuses. This, too, is a central piece of the Caring Campus Project approach; student leaders are provided with time to get to know one another, they attend regularly scheduled meetings where socialising is significant, and they have a chance to work collaboratively with others. Several students noted that they made important friendships while participating the Caring Campus Project and connected with people they otherwise might not have met.

Student engagement is encouraged by an understanding of how students learn and relate to their peers and their broader world. For example, as the contemporary post-secondary student group has grown up with unprecedented exposure to technology and prefers to access information electronically, they expect information to be available at all times and from anywhere. As the goal of the Caring Campus Project was based on reaching and engaging students, the relationship of students to technology needed to be taken into account when working with student leaders and when planning events for the broader campus community. It also needed to be sensitive to how technology was used by students and stay abreast of changes. For 
example, while student leaders favoured social media (and in particular Facebook) for communication with the broader student body, they indicated that Apps related to substance use and health likely would not be widely received and used by the student population.

\section{Engaging male students}

Although student engagement principles apply across genders, there are several differences in the engagement of female and male students. Male students may be vulnerable to a narrow understanding of what it means to be a male; that is, they may be influenced by a hegemonic definition of masculinity.

Recently, gender based public health initiatives have looked at how to engage men in gender-based violence initiatives; however, knowledge about how to successfully engage men is applicable to other topics. A great deal of stigma is associated with masculine mental health problems, and it is a challenge to get men to take an active role in this area (White, Seims, \& Roberstson, 2015). Providing opportunities to talk about how many men struggle with mental health problems can encourage men to be more open about their experiences. At all of the Caring Campus Project sites we had male student leaders who were willing to talk about their own mental health issues and this created space for other people to share their thoughts. Language is important when engaging men in mental health conversations; framing issues around stress and life functioning can feel less stigmatising than talking about mental illness (White, Seims, \& Roberstson, 2015). This applies to substance use as well; finding language and ways of talking about substance use that are acceptable to students is essential. Sharing stories is a useful tool to encourage young men to participate in dialogue about subjects they may not be comfortable with or may not have much experience talking about (Man to Man, 2009).

Finding students who are perceived by others as leaders can pave the way to engaging young men. This was crucial at all our Caring Campus Project sites and we were fortunate to engage students who were well connected on campus to take on visible leadership roles and recruit other students who otherwise might not have gotten involved.

\section{Running a student summit}

\section{Recruitment and advertising}

Key Questions: 
- How will you get the word out about The Caring Campus Project?

- Where/how will you advertise for the position of male student leader?

- How can you describe the position of male student leader appealingly?

The recruitment for male student leaders may take several different forms depending on the most effective way to reach a broad number of students on the campus. Recruitment at this stage may be difficult as no one has heard of the project and there is no established social media presence to draw on. Some of the methods that can be considered include posting on online job boards, advertisements in student newspapers, direct emails to students, listings in student newsletters, and connecting with other campus clubs.

How the leadership positions are described may impact who is interested in the project. Presenting the positions as a "job" with a list of required skills and competencies can make the role seem substantial and helps it stand out from other club positions and volunteer opportunities. Our job postings utilised the Movember brand and, where applicable, advertised compensation included in the position. Additionally, the job postings mentioned the approximate length of commitment, the main themes/objectives of the initiative, and specified that applicants had to be male-identified.

Like a job posting, the requirement of a cover letter and resume allowed the Project staff to get a good sense of the applicants. We found that asking potential student leaders to describe their interest and motivation for working in this area enabled many to describe their own, or their friends' experiences with substance use and misuse, providing an opening for dialogue and discussion. Indeed, several student leaders who disclosed their experiences in cover letters went on to participate in contact-based education activities. Following collection of the applications we conducted interviews with the students to assess the project-person match and provide students with additional information about what would be expected of them.

Examples of job postings for student leader positions are included in Appendix B.

\section{Planning the summit}

Key Questions:

- What are the goals of the summit?

- When and where will the summit be held? 
When and where will the summit be held? The goals of the summit should be set out in advance so that the schedule for the event reflects these priorities. The goals set out for The Caring Campus Project summits highlighted two priorities: (i) what knowledge project staff needed to communicate to the students and (ii) what the students would accomplish over the course of the summit event.

The project staff were expected to:

- Provide information about mental health and substance use;

- Share information about types of evidence-informed interventions;

- Show examples of other successful initiatives;

- Provide information and statistics about substance use on each specific campus

- Highlight relevant campus resources.

- Encourage students to consider a broad range of types of activities (eg. social media, policy, community events, etc.)

- Identify with student leaders how project staff can best provide support as they move forward with their activities

Student leaders were empowered to:

- Define an overall project vision and mission statement;

- Identify long and short-term goals;

- Create a brand (images, slogans, messages);

- Consider how their leadership would fit into the overall campus environment;

- Brainstorm events and initiatives.

Goals will change depending on the intent of the project, current campus resources, and the interests of the students present; however, having guidelines prepared prior to meeting with the students will help with the planning of summit activities.

The location for the summit should be somewhere convenient for all participants. All of the Caring Campus Project summits were held on campus in order to accommodate students. All the summits where scheduled for a weekend so that they did not conflict with classes. For example, one summit spanned over a Friday evening dinner and a full day workshop on Saturday. It is important to decide expectations related to attendance at the summit and how or if you will accommodate students who are interested in being involved but unable to attend. Providing food was a popular addition to the summits. In one summit a university 
principal was invited to attend and socialize with the leaders over lunch as an informal but powerful way to highlight the importance of the work.

\section{Facilitation of the summit}

Key Questions:

- Who facilitated the summits, and how was facilitation applied?

Facilitation of the summits was split between project staff at the sites and outside facilitators who were brought in to assist in the process. Project staff used the initial part of the summit to provide students with overall information and context for the project and to present information about mental health and substance use on postsecondary campuses generally, and in the specific setting. The full day meeting was facilitated by a young male who was familiar with the campus and the community and who would be easy for the students to relate to. Each site chose someone they felt was a good fit and the project team met the facilitator to explain the project and the goals prior to the summit. One of the main considerations in bringing in someone else was to have a young male leading the conversation with the male students.

The facilitator was responsible for guiding the students through a number of different activities designed to address the previously determined goals of the summit. The activities and structure of the day was largely left to the facilitator to determine based on his own experience and preference. For example, in one summit the facilitator had students working in groups to develop important ideas for the mission statement, and to brainstorm potential initiatives around action plans. After the summit, the facilitator met with the project staff to discuss the process and also provided a written report describing the day and the outcomes.

\section{After the summit}

Key Questions:

- What are strategies for moving forward: plan for communication.

At the conclusion of the summit there should be a plan in place for moving forward. This plan will include strategies for communicating goals and actions and what projects each student leader (or team of student leaders) will be responsible for. There is a lot of enthusiasm at the end of a summit and it is a good time to make plans to execute goals quickly to capitalise on the momentum of the day. Following the summit, each site can establish how often the team should meet and everyone should know what part he will play in the effort to achieve the set goals. 
Having a range of short and long-term goals is helpful. It is important to consider how the initiative can move quickly to establish the presence of student leaders on campus and to provide early feedback related to running related activities. We found that although the school year runs over 8 months, there is a limited window of opportunity to advance student lead activities given the time demands of exam schedules and holidays.

\section{Branding and challenging masculinity}

\section{Redefining masculinity}

Brand selection revealed student perceptions of the impact of a brand name. Each of the Caring Campus Project sites took a different approach to creating their brand. Two of the groups chose a name with a gender focus and the other site chose a gender-neutral title. The students at the two sites where the brand was gendered were drawn to the idea of trying to "redefine" the meaning of a phrase that previously was associated with negative masculinity.

Queen's for the Boys: The name "Queen's for the Boys" originated with the social media subgroup, of the student leader group. The idea at Queen's University was to try to reclaim and redefine the popular phrase "for the boys," which was associated with negative connotations such as binge drinking, objectifying women, and conforming to negative ideals of masculinity.

Man Up for Mental Health was the brand student leaders chose at the University of Calgary, based on a common expression that has historically been associated with masculine ideals of being "tough" and "sucking it up." The student leaders wanted to reinvent this idea to promote the idea that "man up" meant being able to take care of those around you and yourself.

PROsocial: The PROsocial Project was the name chosen at Dalhousie University to focus on language that was gender neutral. Their student leaders felt that it was important for their campus that the project not be seen as exclusively for men. Students highlighted the importance of spreading the messages about men's mental health to the entire community so that female students would be able to encourage their male friends to be more open about mental health and substance use. 


\section{Capitalising on a known brand (Movember and Bell's Let's Talk)}

The Caring Campus Project was privileged to be connected to another recognisable brand, the Movember Foundation. As a leader in men's health, the brand and the signature mustache promotions are well known across all campuses. The students were conscious about capitalising on this chance to raise awareness of their project by using recognised logos and symbols. Not all the sites directly incorporated the mustache into their logos (see Figure 3-1); however, the Movember logo was used across social media and websites.

In addition to the Movember brand, the initiative benefited from national advances in destigmatizing issues related to mental health. Specifically, the growth and broad appeal of Bell's Let's Talk campaign, provided an avenue for student leaders to advance awareness of substance use on post-secondary campuses. For example, on one campus students used white boards to engage students in dialogue about "what it means to be 'for the boys' " as part of the Let's Talk Day campus activities.

\begin{tabular}{|c|c|c|}
\hline Queen's University & University of Calgary & Dalhousie University \\
Queen's for the Boys & Men Up for Mental Health & The PROsocial Project \\
\hline & &
\end{tabular}

Figure 3-1. Logos of student-led initiatives at each site

\section{Awareness}

Each student leader group employed a multipronged approach to raise awareness of its brand and the activities associated with that brand on campus. Social media and the use of an identifiable hashtag were employed, with Facebook, Instagram, 
and Twitter being used to create a following of students that could be targeted for events and initiatives, and to connect with stakeholders who could be called upon to help support events and spread messages through their own networks. Connecting specifically with campus groups that shared similar goals was also important in spreading information about the project.

At each campus, the students invested significant time raising awareness about the project through in-person events. There were numerous opportunities on campus for the groups to set up presentation booths at larger events related to mental health, and this gave the young men a chance to talk to other students about why they were involved in the Caring Campus Project and what they were hoping to achieve on the campus. In addition to these larger activities, students also set up booths on the campus throughout the year and handed out information, swag, food, drink, reaching an even larger number of students.

\section{Challenges and tensions}

\section{Institutional barriers}

The Caring Campus Project faced different barriers at each institution in which it operated, which required constant negotiation throughout the implementation of the program. The following examples show the kind of challenges such an initiative must overcome to attain its goals.

Queen's University

The Queen's group was lucky in the sense that it received considerable institutional support, both from the upper levels of administration, as well as from leaders and resources within the mental health and student wellness community (such as Student Wellness Services). This campus likely benefited from having very high profile mental health initiatives and resources on campus. For example, the presence of Bell's Chair for Mental Health and Anti-stigma research on this campus contributed to the profile of the Caring Campus goals, objectives and processes. Navigating the campus field with multiple stakeholders was be tricky in that leaders didn't want to "step on anyone's toes", but overall the feeling at Queen's was positive and supportive. Yet, project staff and student leaders still worked hard to ensure that relevant stakeholders were aware of Caring Campus activities and that there were ongoing efforts to engage all stakeholders in moving beyond an 
individual focused model of support and public health to one prepared to address the campus culture.

\section{University of Calgary}

One of the initial barriers at the University of Calgary was gaining access to student email addresses in order to conduct the program evaluation survey. Due to privacy agreements in place there was no way to directly email students so alternative arrangements had to be made. The result of this limitation was a poor response rate to the program evaluation survey.

A second barrier was getting access to space on campus for students to host their events. All the spaces on campus that would suit the needs of the event were costly and required the students to negotiate complex bureaucratic structures to arrange access. This made it difficult for students to plan autonomously and to execute events. In addition to the expense of the space, other event costs, such as catering, were high. Students were not allowed to bring food in from off-campus and had to go through campus catering for all events. These expenses compromised the ability of students to raise funds when hosting an event on campus.

\section{Dalhousie University}

Although the project initially faced resistance from the university in regard to the email survey focusing on substance use on campus, the administration eventually allowed the survey to be sent to the student population. There was recognition that the survey would contribute important information regarding mental health and substance use.

Another tension existed within the student residence concerning the message that "positive drinking practices should be observed," as discussions of partying were not generally implemented. The team at Dalhousie negotiated this issue with Student Services and all their posters were approved, resulting in the student residence authorities being more comfortable with the messages. This illustrates the importance of bringing policy makers and stakeholders into the conversation as early as possible to ensure that the messages and aims of the program are supported.

\section{Partnering with other programs/clubs/initiatives}

What agendas existed on each campus already? Before attempting to implement a program, we took the time to look at what already existed on campus that addressed 
similar issues and considered how our program could meet unmet needs or complement existing groups.

The universities targeted by the Caring Campus Project had numerous groups and student clubs that addressed mental health. Some of these were chapters of larger initiatives, such as Jack.org, and others were campus specific initiatives.

Additionally, there were institutional programs that addressed mental health, such as campus medical response teams, and centres on campus that catered to particular groups of students (such as Women's Resource Centres, International Student Centres, LGBTQ+ Centres) and often provided different types of mental health support.

Developing partnerships and collaborations with these groups was an essential aspect of integrating student led activities in broader campus structures and activities, and generally to increase the legitimacy and acceptance of student leaders and their activities. With the project's focus on gender sensitive and gender transformative approaches to addressing substance use, these partnerships promoted working relationships and collaborations between male student leaders and other university initiatives focused on gender relations. For example, one student leader group developed close working relations with the local White Ribbon campaign group, providing a platform for male student leaders to engage with other students around issues related to substance use and violence against women.

\section{Concerns over "men's groups" on campus}

Key Questions:

- Who was concerned and why?

- Who/what groups wanted to talk about gendered concerns?

- What components of the program were men-only vs. all students?

There was some concern raised by members of the campus over the formation of a group that was viewed as "for men only". It was necessary to explain what the mandate of the Caring Campus Project was and why the focus was on male students. The students also had to consider which parts of this program were going to be geared toward male students only and which events would be open to all students.

Membership as a student leader was restricted to male-identified students only, and this was a condition of the initial funding received. However, all of the events and initiatives the students ran were open to students of all genders. This helped to make other people on the campus more comfortable with the overall project and to raise awareness about the connection between substance use and mental health for 
all people. While involvement in the initiative following the funding period will likely not be gender specific, how the ideals of gender transformative beliefs and norms related to substance use and mental health will be sustained will require ongoing attention and consideration.

\section{Student commitment}

Key Questions:

- How to effectively communicate with students?

- How to hold someone accountable in a "volunteer" role?

Student-led events and activities require considerable student input. Students are extraordinarily busy and many of the students who were motivated to get involved in this project also occupied other positions of leadership on campus, held job(s), had heavy academic demands, and all had personal lives. Although it is understandable that students with so much on their plate would occasionally not be able to follow through on everything planned, lapses in student performance regarding planned events created tension throughout the project. Strategies for accountability included: getting the students to track their hours with a welldefined reporting and process, emphasising expectations with respect to performance and communication, and using communication methods that best suit students.

\section{Supporting male student-led initiatives}

\section{Different kinds of support are required for different activities}

Considerations:

- Financial support,

- Logistical support.

The project staff needed to be flexible and be able to adapt to current needs. For example, project staff were vital in obtaining financial support to execute campus activities and to surmount many logistical barriers and challenges to project realisation. Because the students were not officially organised as a recognized university club and could not directly book space, project staff were required to process such bookings through a university department. Project staff also ordered supplies and paid for project related expenses. Contracts for space, speakers, foods, and other activities all needed staff involvement. 


\section{Challenges for campus activities}

Considerations:

- Space,

- Cost,

- Competing programs.

Campus space is limited and access to centrally located, accessible, highly trafficked areas is limited. A number of different groups might desire simultaneous access to the same space. Therefore, the only space available can be less than ideal for the intended purpose. The cost of running large campus initiatives is also a significant challenge. Speaker fees can be quite high and, due to contractual obligations, food and beverages had to be ordered at high prices from the campus catering company in some campuses. For example, in University of Calgary, when students wanted to buy pizza from a discount pizza shop near the campus and hand it out to students after they had been drinking, this was not allowed. Students were not allowed to hand out food, so a hospitality staff member would have to be hired.

Ideally it would be great to create connections with all the other mental health related organisations on campus, but this is not always possible due to the sheer number of other organisations, ownership over certain events, and the challenges of getting such a large number of people to coordinate their activities. To connect with other groups on campus, students articulated what was unique in the Caring Campus Project. Although many other groups addressed mental health, the Caring Campus Project emphasised the harm that can be associated with substance misuse, the links between mental health and substance use, and drew attention to gendered patterns of substance use. Positioning our work at this intersection allowed the Caring Campus Project to fill a gap on the three university campuses.

For more information about the process of student engagement in the Caring Campus project see the following article in the special supplement of the Canadian Journal of Community Mental Health:

Krupa, T., Henderson, L., Horgan, S., Dobson, K., Stuart, H. and Stewart, S. (2018). Engaging male post-secondary student leaders to apply a campus cultural and gender lens to reduce alcohol misuse: Lessons learned. Canadian Journal of Community Mental Health, 47. 


\section{Module Four: Social Norms Messaging}

\section{Social Norms Theory}

Social norms refer to individuals' perceptions of the behaviours and attitudes of others in their reference group. Social norms theory in the area of substance use suggests that what is perceived, as the "norm" is usually an over- or underestimation of what is true. Moreover, these norm misperceptions can have a powerful effect on behaviours as people often strive to meet the norm (Miller and Prentice, 2016). If students overestimate the frequency of drinking and the quantity of alcohol consumed by their peers they may drink more than they otherwise would to feel part of the group. These misperceptions have been thought to contribute to the high rates of drinking on post-secondary campuses, as students strive to conform to the misperceived social norm. A social norms approach uses a variety of methodologies to provide normative feedback to communities, groups, and individuals as a way of correcting misperceptions that may influence behaviour. It can be targeted to reduce problematic drinking behaviour or increase healthy behaviours such as setting limits on the number of drinks consumed. The goal is to reveal and enhance already existing healthy norms that have been underestimated and weakened.

\section{Social Norms Messaging}

Social norms messaging campaigns are one approach to rectify norm misperceptions (Andreasen, 1994; Previte, Russell-Bennett, and Parkinson, 2015). This involves disseminating targeted messages that encourage individuals or groups to change their behaviour. The assumption is that by providing students with accurate information about students' drinking norms it will be possible to correct overestimates of drinking patters and this will result in a reduction of students drinking as they are no longer trying to live up to a misperceived (overestimated) norm (Burchell, Rettie, and Patel, 2013).

Social norms interventions may be targeted to an entire group or community (such as through a broad based social marketing campaign), targeted to high-risk groups, or designed to give personalized normative feedback to individuals so that they can compare their patterns of behaviour to the larger group.

Social norms messaging is unlike traditional substance use education in that it does not use scare tactics, dos not contain a moral undertone on how the population 'should' behave, is a participatory process that includes members of the target group 
and operates by praising the healthy behaviours of the majority, rather than focusing on the negative behaviour of the minority. Social norms messaging is most effective when it is part of a more comprehensive approach (Burchell, Rettie, and Patel, 2013).

Social norms messages should be positive (beneficial, constructive, optimistic), inclusive (focus on a target group, sensitive to local values and culture), and empowering (encourage self-care and reliance, energize, take a proactive stance).

\section{How to Design a Social Norms Messaging Campaign:}

Step 1: Conduct a survey of the intended population to:

a. Establish what the actual norm of the given behaviour is in the population of interest.

b. Evaluate if there is a misperceived norm.

c. Assess if this misperceived norm corresponds to hazardous drinking patterns.

d. If you do not identify a misperceived norm that is associated with hazardous drinking, then a social norms approach is not likely appropriate for your site.

Step 2: Design social marketing messages

a. Draw on your data to identify the behaviors you would like to target. The behaviour or attitudes you include in your message should be endorsed by the majority, 65\% of greater, of the population (e.g., Most students on our campus do not binge drink)

b. Determine a theme for your campaign that will be visibly displayed on all of your posters and materials, to provide it with a unifying theme and recognisability.

c. The message should be simple and honest and should be written in the language of the target audience

d. Provide the source of data on your marketing tools. This will help the target audience view the message as credible, relevant, local, and of importance to them.

e. The social norm message should be prominently displayed. Develop several key messages using the principal of PIE (Positive, Inclusive, and Empowering). Note that "shock graphics" or those that grab the attention of the audience, as it relates to harm caused by the behaviour being examined, should not be used 
(e.g., student vomiting in a toilet). These images are not in line with the PIE concepts that aim to promote positive behaviour.

i. Positive: messages are achievement oriented towards what a healthy population does. They lay out healthy behavior and protective strategies. The messages are beneficial, constructive, and optimistic for the audience.

ii. Inclusive: messages are intended for everyone in the target population and are sensitive to the behavioral and cultural needs of the target population.

iii. Empowering messages encourage people to act for themselves to solve problems and take charge of their own behaviours. Messages identify the resources and self-care options available and can provide real examples of success from others in the target population. The messages are strengthening, empowering, and energizing.

iv. Collaborate with representatives from the target population (e.g., students) to help develop the messages.

Step 3: Decide on a dissemination strategy to reach your population and pilot test it.

a. Include a variety of dissemination strategies to maximize your reach such as social media, posters, seminars, and talks. The medium for delivery is an important consideration as the target audience may not be used to a traditional poster format and may be more engaged by something else, like a Facebook messaging campaign.

Step 4: Test if the marketing reached the intended population

a. Conduct a follow-up survey of the intended population asking the same questions to observe behaviour changes

b. Ask if the participants saw the social norms marketing campaign

c. Conduct a survey close to the end of the poster campaign

Step 5: Test if any changes occurred, including for example:

a. Decrease in actual drinking?

b. Decrease in a misperceived norm? 
c. Increase in protective behavioural strategy use?

d. Decrease in harms associated with substance use?

For more tips on developing your social norms message, see Haines, Perkins, Rice \& Barker (2005).

\section{Challenges in Developing A Social Norms Messaging Campaign:}

\section{What if You Can't Collect Local Norms?}

Depending on your environment, it may be difficult to collect survey data with a high enough response rate to make the norms credible. In the Caring Campus initiative, for example, response rates ranged from $6 \%$ in Calgary, to $26 \%$ at Queen's, to 32\% at Dalhousie. Administrative issues can challenge the process of data collection and contribute to a low response rate. In response to these issues data collection can end up focusing on convenience samples of students.

\section{What if There is No Healthy Norm to Report or if Perceptions are Correct?}

Social norms messaging assumes that there is an underlying health norm that has been hidden from view that can be uncovered using local survey data and then disseminated to shape behaviours. But, what if there is no healthy norm to report? In the Caring Campus project, we noted that almost half (45\%) of students at all sites reported a hazardous drinking pattern.

A second problem was that in campuses where hazardous drinking patterns were the highest, male students tended not to misperceive the norm. For example, at Queen's University, virtually none of the first-year males and a third of the females misperceived the drinking norm. Similarly, at Dalhousie, only about $10 \%$ of first year males misperceived the drinking norm. In these cases, social norms messaging regarding drinking patterns cannot be expected to lead to any meaningful change; since they are not misperceiving behavioural norms there are no adjustments to perceived norms to be made.

However, the Dalhousie team noted there were also some encouraging statistics regarding students' prosocial behaviors in terms of willingness to help one another with mental health and substance misuse issues. Based on these survey findings, the research team designed five main positive, "prosocial" messages to be disseminated on campus (see figures below). Note that many of the social marketing suggestions 
above were used in designing these posters. This included ensuring the message was the main focus, providing the data source, ensuring graphics were inclusive for the target population, providing empowering information to students, as well as ensuring a common (prosocial) theme throughout all the posters which included ensuring the Dalhousie PROsocial Project logo was visible on all posters.
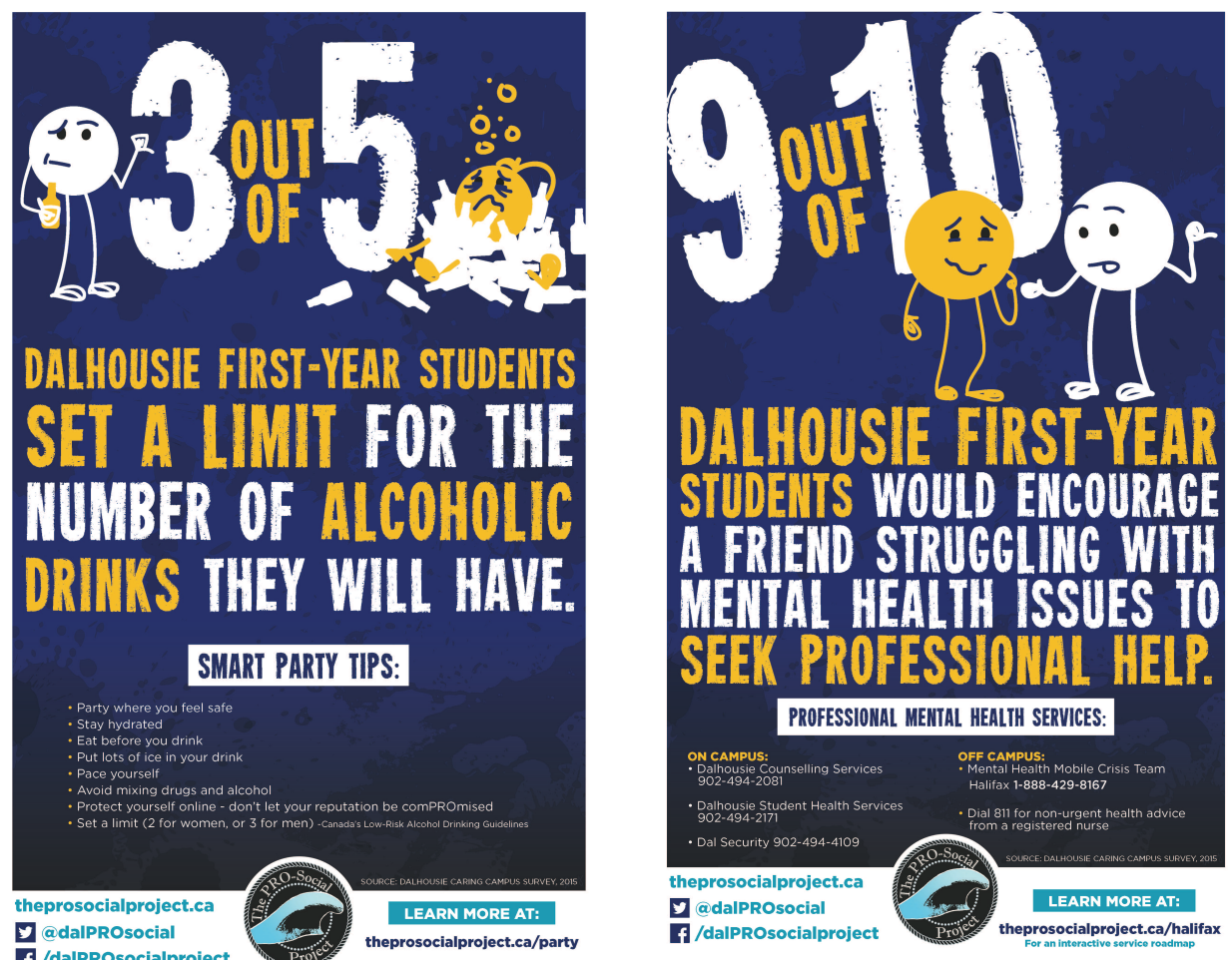

In the posters above, the first is perhaps the better candidate for social norms messaging related to drinking patterns because it shows that about $60 \%$ of students would set a limit for the number of drinks they will have. Thus, there is still considerable room to move for the $40 \%$ of students who may not practice this safe drinking tip. In the second poster, virtually all of the students would help a friend struggling with mental health issues to seek professional help. While the poster reinforces prosocial behaviour, it is unlikely to result in a shift in behaviour as would be predicted by social norms theory owing to the ceiling effect. 


\section{Summary}

Social norms messaging may not be as straightforward as often thought given the complexity of developing and interpreting norms, and the possibility that healthy drinking norms may not exist on a post-secondary campus. In this project, we learned that social norms messaging may not be appropriate for every location. It may be possible to modify the messaging to incorporate other positive messages that can be identified in the data.

For more information about the social norm component of the Caring Campus Project see the following article in this special supplement of the Canadian Journal of Community Mental Health:

Narain, T., Stuart, H., Krupa, T., Stewart, S., \& Dobson, K. (2018). Questioning the Social Norms Approach for Alcohol Reduction in First-Year Undergraduate Students - A Canadian Perspective. Canadian Journal of Community Mental Health, 77. 


\section{Module Five: Contact-based Education}

\section{Contact-based education: Theories and principles}

\section{What is contact-based education?}

Contact-based education refers to the involvement of individuals with lived experience of specific health or social conditions in sharing their personal stories with target audiences. Contact-based education in the Caring Campus Project had current or newly graduated male students tell their story of substance use to other students. The student related how he realised that substance misuse was a problem, how it impacted his life, and ultimately how he managed it and was able to move on in his studies and other aspects of daily life. Such personal stories can help other students to look inward to assess the risks they might be taking in their own substance use. They can also help reduce the stigma associated with substance misuse.

\section{How has contact-based education been applied and what is the evidence supporting its use?}

Contact-based education has been used as a strategy to improve interactions between members of the general public and those experiencing disadvantage, discrimination, and stigma. It has been used extensively to reduce the stigma of mental illness, where trained speakers with lived experience of a mental illness share their personal recovery stories with target populations and engage in active dialogue to promote experiential learning. Broad literature reviews have reported that, compared to other approaches (such as traditional didactic education), contact-based education resulted in the greatest improvements in knowledge, positive attitudinal change, and behavioural changes in members of the public who hear these stories. Corrigan and colleagues demonstrated that contact-based education can reduce the stigma of mental illness among college students (Corrigan, et. al., 2014). The Mental Health Commission of Canada's Opening Minds Initiative (hereafter, Opening Minds) identified contact-based education as a core element of all its public interventions to raise awareness of and reduce stigma associated with mental illness. Opening Minds focused on reducing the stigma of mental illness in four target groups: health providers, workplaces, the media, and, most relevant to the Movember Caring Campus Project, young people. 


\section{What are the potential benefits of contact-based education applied to substance}

misuse on postsecondary campuses?

Despite its prominence in the mental health field, contact-based education has not been widely used as an intervention strategy to address issues related to substance use among young people. However, if the audience is able to identify personally with a speaker, to empathize with speakers' experiences, and to be inspired by messages of recovery and growth, positive changes in attitudes, knowledge and behaviours are likely to occur. Therefore, such contact-based education could be a powerful intervention approach to help students:

- become aware of substance misuse as a problem requiring attention on campuses;

- link substance use to issues of mental health and well-being;

- reflect on their personal attitudes related to substance use;

- recognise substance use and mental health issues experienced by other students and how they might support these students to affect change;

- become familiar with informal and formal supports and resources available to assist with substance use.

- reduce the stigma that surrounds substance misuse

- positively influence the campus culture

- act on behalf of their own well-being

Although high-levels of substance (primarily alcohol) use appear to be the norm on postsecondary campuses, open and planned dialogue about the impact of substance use on individuals and campus environments is rare, possibly because there is considerable stigma associated with substance misuse. This stigma may be related to generally held views that problems with substance misuse are a sign of personal weakness or failure, even in environments where substance use is high. Contactbased education encourages dialogue and such dialogue can reduce the stigma that surrounds substance misuse.

Contact-based education that is formally organised and integrated within campus structures has the potential to positively influence the campus culture related to substance use. Students with substance use issues are no longer "invisible while in plain sight," and respect for a larger range of experience and choices related to substance use on campus can increase acceptance of the need for substance-free campus activities. 
To the extent that contact-based education is implemented and integrated by student groups, the Caring Campus intervention might mobilise and empower students to act on behalf of their own well-being. This latter point is particularly important given that students can be highly sensitive to any indication that postsecondary institutions are trying to control their private lives and activities. This Caring Campus Toolkit has been designed to encourage influential student groups to integrate contact-based education about alcohol misuse into their routine activities.

\begin{tabular}{|l|}
\hline Elements of contact-based education that are likely to effect change \\
\hline - The audience is able to personally identify with the speaker. \\
- The speaker clearly describes the difficulties with substance use, its relationship \\
- To mental health, and the consequences of misuse. \\
- The speaker presents messages of hope and recovery. \\
- Speaker and between members of the audience. \\
- structures to reach the student population. \\
- groutact-based education is integrated with the work of established student \\
Students actively participate in the development and dissemination of contact- \\
based education on the campus.
\end{tabular}

\section{Designing and implementing contact-based education focused on substance misuse on postsecondary campuses}

\section{Contact-based education program planning}

Planning a contact-based education (CBE) initiative on a postsecondary campus involves consideration of the nature and range of CBE opportunities to be developed and implemented across the campus. CBE can be started as a general initiative, then further developed to meet specific needs. For example, planning might consider:

- What different forms will CBE take?

- For example: CBE can be delivered in the form of (i) directly to a live audience, (ii) video recordings of personal narratives available for dissemination, (iii) a documentary format that captures several personal stories in an organised way, and (iv) personal stories uploaded to social media sites such as YouTube. 
- Are there particular groups on campus that could benefit from targeted CBE?

- Research has indicated that particular patterns of substance use exist within specific academic programs/student groups, such as engineering, business, varsity athletics. It may be useful to consider having a range of personal stories that can capture the experience of students in these different programs.

- Are there particular activities/locations on campus associated with high substance use? Should CBE be developed to target these?

- Negative consequences associated with substance use might be linked to orientation activities, residence living, alumni or homecoming weekends. CBE could be focused on such activities.

\section{Speaker recruitment, training, and support}

The recruitment of students willing to speak about their experiences with substance misuse and related impacts will require careful planning, particularly early in the process of establishing the CBE initiative. Think about: (i) How you will access students to publicise the CBE initiative? (ii) What information will students receive about the initiative? (iii) What issues related to informed consent and privacy need to be addressed?

Institutional email is perhaps the best way to send information to all of the student body but may be restricted by policies regulating the use of this system. Connecting with students through student health and wellness services is an option, but the message might be restricted to students who use these services. Regardless, health and wellness services can provide important advice about specific issues to consider for a particular campus, and they can advocate and advertise the CBE initiative through their networks and connections. Accessing students through existing mental health awareness initiatives is another potential vehicle for recruitment, but it is important to highlight that the CBE initiative is focused on advancing awareness and dialogue specific to substance use and its link to mental health.

Recruitment invitations can include the following:

- A brief summary of the nature of the problem of substance use on postsecondary campuses,

- A brief summary of contact-based education and its intended impact related to substance use,

- The potential benefits of participation in the CBE initiative, 
- Assurance of structures to support student participation and well-being,

- A statement indicating that students retain control of what they will share, information about student consent, and a guarantee of ethics approval.

\section{Building a supported and engaged team of CBE speakers}

A team of CBE speakers related to substance use on postsecondary campuses will provide a foundation for the CBE initiative, maintain student engagement in the CBE initiative, and provide an infrastructure to sustain the CBE initiative over time.

Speaker team building includes:

1. Clarity with respect to the role of student speaker in contact-based education and reflection on the benefits of participation. Early and ongoing dialogue among student speakers can centre, for example, on the following questions:

- What motivated you to get involved in this initiative?

- Did your involvement in the CBE initiative hold any special meaning for you?

- What does it mean to be part of the speaker team?

- What does it mean to you to provide contact-based education on your campus?

- How did telling your story impact your life?

- What insights did you gain about yourself when sharing your story with others?

- What was it like for those who shared your personal stories?

- What did you learn from participating in CBE?

- Is it difficult to provide CBE?

- What specific challenges did you experience in providing $\mathrm{CBE}$, and how did you manage the challenges?

- Would you encourage other people to become involved in CBE?

- What supports/resources are particularly helpful to you to enable your participation as a CBE speaker team member?

2. Building intergroup cohesion

Consider how the location of group meetings will impact group cohesion. Locations that facilitate dialogue and privacy while being experienced as comfortable are best. Opportunities to engage socially as a group outside of CBE activities can encourage cohesion and investment. In one of our sites CBE social activities included attending a comedy club and an evening of bowling. 
3. Participatory strategic planning

Consider developing the group's investment in the initiative by engaging them in specific planning activities related to CBE. This could include identifying CBE activities on campus, locating and networking with potential partner groups on campus, developing a campus specific mission and objectives, developing and monitoring a timeline for initiatives, planning for sustainability of the initiative.

\section{Developing and delivering personal stories}

Effective public speakers are skilled and well-prepared. This applies to CBE where speakers must not only deliver impactful presentations, but also must attend to their own well-being in the course of sharing personal information. In evidenceinformed contact-based education, the preparation of speakers and their speeches is deliberate and planned. Speakers are offered guidance and are provided with guidelines to develop their stories in a way that is authentic and is likely to have a positive impact on the audience. See Appendix C Speaker Training Guide used at Queen's University site.

Individual student stories are typically constructed to be 10-15 minutes long. In the mental health field, research has shown that the creation of a narrative includes several steps:

- constructing the story,

- developing a first draft,

- receiving feedback,

- refining and editing,

- practicing delivery of the story,

- delivering the story to target audiences.

Where CBE is established, new speakers can be introduced to the process by attending existing speaker events. Whenever possible, a speaker should have an opportunity to debrief following a speaking event; debriefing is an opportunity to receive support, to reflect on the event, and to make note of ideas for future presentations. Appendix $\mathrm{C}$ provides a template of questions that can be used to help students develop their stories in a supported context.

In the Caring Campus Project, an integral element of the CBE initiative is to deliver personal stories that touch candidly on substance use on the postsecondary campus. However, speaking about personal experiences with substance use can be difficult for students, and without direct attention, stories can easily be developed to offer 
only a cursory mention of substance use. Indeed, in our first CBE efforts, students tended to offer minimal direct discussion of their experiences with substance use, focusing instead solely on their mental health. With this in mind, speaker preparation should attend to helping students develop and deliver their speeches with several of the following critical elements.

- Identification of how substance use patterns/behaviours presented in real life experience (i.e. giving an image of it as problem behaviours and patterns)

- What was the meaning of the substance use for the speaker - eg. Peer pressure, socializing, masking mental health issues, identity, etc.

- Specific and explicit connection between substance use and mental health

- How mental health was impacted by substance use

- Relate substance misuse to other consequences in the speaker's everyday life. For example, did it affect his academic achievement? finances? Were there legal consequences?

- What does controlled and responsible use of substances look like?

- What is the difference between substance use (responsible use) and substance misuse?

- What strategies helped the speaker address his substance misuse and, if applicable, his mental health issues?

- What informal supports and resources were helpful?

- What formal supports and resources were helpful?

- What personal coping strategies were helpful?

- How does substance use factor into the speaker's life now?

In developing personal stories for contact-based education, students are asked to consider a few key messages they would like to clearly deliver to their audience. These messages can be embedded in the talk, but they can also be used to create a powerful summary/conclusion. Examples of key messages consistent with the objectives of contact-based education that address substance use and mental health issues on campus include:

- There is a significant relationship between substance use and mental health;

- Recovery from substance misuse is possible;

- Formal and informal supports for substance misuse are available and can help;

- There is no shame in using supports and mental health resources;

- You are not to blame;

- Substance misuse can happen to anyone just like mental health issues can impact anyone; 
- The campus culture promotes substance use, including excessive substance use;

- It is easy to fall under the radar in a postsecondary setting due to the normalcy of drinking or using substances (hidden in plain sight);

- It is important for you to check in with yourself and personally reflect on your substance use behaviours and mental health.

\section{Ethics, consent, and privacy}

Although postsecondary student participation in contact-based education is voluntary - a choice made by competent and informed young adults - ethical issues will emerge and need to be considered in an ongoing way.

In the recruitment phase of this project, students need to be assured that they will be in control of their personal story-what they are willing and able to present to audiences - and that, to the degree that sharing in a public context allows, their privacy will be respected.

CBE program planners are encouraged to submit their plans for ethics approval to a university/college ethics board. Ethics approval is mandatory if CBE efforts will be subject to evaluation or research, but beyond seeking formal approval, ethics boards can offer valuable feedback and suggestions related to consent and privacy.

Privacy issues should be addressed directly with students and informed consent should be obtained from each student. All prospective CBE speakers, even those who are eager to share, need to reflect carefully on the potential implications of the information they share. For example, they can be encouraged to consider the implications of their stories on their friends and families, the extent to which their stories include and implicate others, and the potential impact of their stories on important activities and roles now and in the future.

CBE can offer student speakers an opportunity to deliver their stories in a variety of ways, each with different implications for privacy and exposure. For example, speaking in person to an audience is an example of high disclosure CBE, but videotaping personal stories can be constructed so that students are more or less identifiable. CBE programs need to consider the extent to which they will offer these different formats and speak to students about how these options can affect privacy and confidentiality. 


\section{Disseminating, evaluating, and sustaining contact-based education}

Dissemination activities need to be carefully considered and planned. They can include activities developed directly from the CBE initiative, or be developed in partnership with established groups and events. CBE planners can partner with the activities of the following types of groups:

- Formal alcohol and substance use committees,

- Social justice and advocacy initiatives emerging from student government,

- Formal orientation groups,

- Residence life groups,

- Mental Health Awareness groups,

- Equity groups,

- White Ribbon campaign initiatives,

- Ted X talks.

The impact of CBE efforts will depend on the overall objectives of the initiative. The "reach" of the initiative can include collecting data about the number of CBE sessions, the number of attendees, the range of students who receive CBE (e.g., across programs, academic year, gender). The evaluation is not meant to "evaluate the speaker," but to give some sense of the impact of the CBE on the audience. A questionnaire delivered to the audience might include the following statements to be rated simply as a yes/no answer or rated as 1 to 5 demonstrating the degree of impact.

As a result of participating in this event:

1. I am more aware of the link between substance use and mental health.

2. I am now more aware of the stigma associated with substance misuse.

3. I am now more aware of some of the signs of substance misuse and associated mental health difficulties.

4. I am better prepared to approach or talk about mental health and substance use with my peers.

5. I know more about the resources and supports that could be helpful to someone with substance use issues

6. I know more about how the campus culture can influence substance use in unhealthy ways

7. I would recommend this kind of event to others. 


\section{Module Six: Program Sustainability}

Achieving the aim of changing campus cultures to foster more supportive environments that reduce substance misuse will take time. It will not happen with a single intervention. Rather, changing campus cultures and having a wider public health impact will take sustained activity over a long period of time. Consequently, 'one-off' activities undertaken by small groups of individuals are not likely to have much impact.

\section{Ingredients for sustainable development}

\section{Developing a workable governance structure}

To be effective the Caring Campus approach requires a well-defined governance structure that provides links to other programs and activities, provides oversight, and ensures that the program delivers on its promised activities in alignment with the objectives. Some combination of individuals must fulfill executive and management roles and oversee decision making. Roles and responsibilities must be defined and structured.

Given the empowerment model that underlies the Caring Campus Project, most students will lean toward a cooperative structure where individuals volunteer to address common goals and objectives. In the first year of the Caring Campus Project, student leaders at Queen's University developed cooperative groups with each group focusing on specific tasks such as website design, media, events, and policy development. The structure of the groups was flat, with no designated leader, though particular individuals did emerge to drive the activities of the group. Because there was no central leadership, groups often worked in different directions, many times with only a few of the members undertaking the activities. Coordination across the groups was lacking such that important events were not featured on the Web page or the social media posts were not integrated with the Web presence. On other campuses, the researchers provided the central coordinating functions and were responsible for the Web presence, developing event ideas in collaboration with the students, and implementing them with student support and assistance. This top-down approach allowed for greater integration of activities across members and more efficient coordination of activities. Thus, the dilemma seemed to be empowerment at the expense of coordination or coordination at the expense of empowerment. 
At the close of the first year of activities, students at Queen's university critically reviewed their achievements and the group structure. All agreed that the cooperative structure built on interest groups had not allowed them to achieve their goals. Their activities were unstructured, lacked coordination, and allowed for specific individuals to shirk responsibilities. An added complication was the fact that all individuals were paid a small stipend from the Project. This meant that members were attracted to the stipend, not necessarily to the activity. Involvement in the group's activities was not uniform and a small number of individuals did most of the work. Two of the emergent leaders worked with research staff to create a structure that defined clear roles and responsibilities for executive members (director and codirector). The director was in charge of operations and the co-director was in charge of finances. The co-director also made the decision that members would be unpaid, as was the case in other student groups across the campus. This would ensure that individuals joined because they were interested and dedicated to the goals of the project. (See Figure 6-1 for the organization structure change at Queen's University)

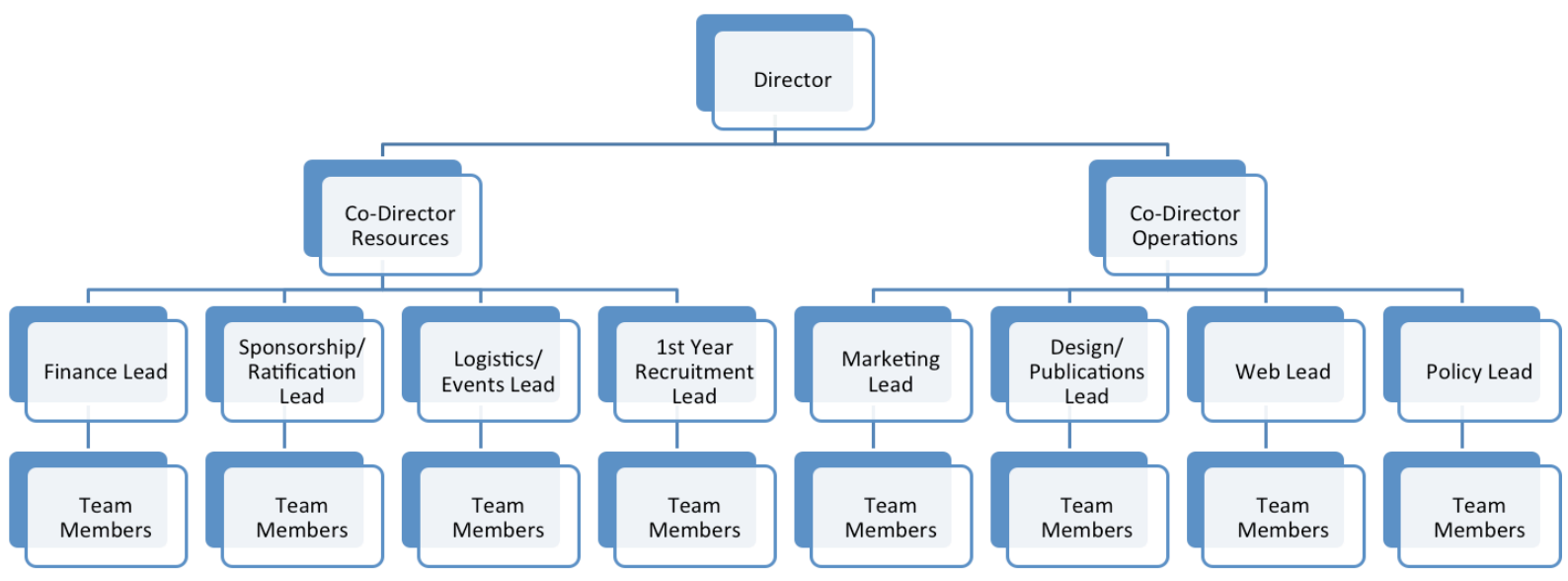

Figure 6-1. Student-leader organizational structure

The initial director and co-director positions were posted by the research team and individuals were recruited into the positions such as a Social Media Lead, a Policy Lead, and an Events Lead. While this may sound similar to the original group structure, the combination of central leadership in the form of Co-Directors, and individual accountability in each of the Lead positions made for a much more 
cohesive and efficient team. They were paid a stipend. They mapped out a series of activities and then recruited interested volunteers to carry them out. Funding was estimated for each activity and funds were extended from the grant to cover the costs.

\section{Funding}

Acquiring regular funding may be the single greatest challenge for student-led wellness programs. The programs with effective governance and program structures and steady financing are the most likely to create permanent change.

The Caring Campus Project started with the support of a Movember grant. This made it possible to hire project staff to help coordinate activities and provide guidance. It also made it possible to support the financial costs of awareness activities, some of which used swag to attract attention and get the message out. Other costs included printing (e.g., large posters; the Substance Use Wellness Tool), videotaping production, and room rentals. To maintain this level and type of activity, regular financing is needed.

Early in the life of the initiative, leaders should carefully evaluate which components of the Caring Campus Project intervention will require resources and begin to look for ongoing support for these elements. Many campuses have funds available to support student initiatives and student-led groups and this is the most straightforward means of obtaining funding. It may also be possible to obtain funding from donations. In some cases, particular functions initiated by the Caring Campus Project (such as a male oriented peer support program) were incorporated into existing structures. It may also be possible to develop partnerships with existing programs and organisations to support activities.

Many Universities also provide the possibility for student groups that meet certain criteria to take part in student "opt-out fees", meaning an additional amount is added to every students' student billing and provided as funding to the groups in question.

\section{Regeneration of student leadership}

Ongoing recruitment and regeneration of student leadership is essential for program sustainability. Attracting individuals with leadership potential and skills must be one of the central administrative functions of the program officers.

Leaders will often arise from the ranks of program volunteers who are implementing activities. Therefore, program leaders must be on the lookout for 
these individuals and provide opportunities (such as the role of co-director or job coach) for them to apprentice. Juggling class requirements and busy social lives with extracurricular activities can be a challenge for younger students. A mix of junior and senior individuals can be an important means of growing leaders into important roles. Rotating potential leaders through different activities can give them a broad view of the program.

In some cases, the program may want to recruit student leaders through a formal job application process (Appendix B: Job posting). This may be viewed as a more fair and transparent approach than promoting someone through the ranks. If the job advertisement is posted on job websites, then the program may be able to attract new individuals who may bring new ideas to the table.

\section{Recruiting for sustainability}

While leadership positions in the Caring Campus project were not primarily filled by first year male students, sustainability efforts required strategic recruitment of new volunteers from first year to ensure continuity. This became an important aspect of student leader activities. The existing leadership were available to mentor incoming student leaders. In addition, project "champions" on the campuses were able to disseminate information about the project and encourage participation. For example, one university had a student rector who was highly invested and involved in the initiative, and able to attract new students.

\section{Maintaining presence}

Part of ensuring sustainability is creating and maintaining a presence that can continuously influence the campus culture, typically through social media and the Internet. An important aspect of this is developing a brand that resonates with the campus culture, is respectful to the target audience, and conveys the main message of the group. A brand creates recognition and links health promotion concepts to activities.

Building up a brand is synonymous with building up a reputation. Thus, it is imperative that interactions are respectful and do not alienate part of the audience or overly politicise events. Branding can build expectations about how people who subscribe to the brand (by displaying it on T-shirts or knap sacks) will behave.

Once branding has been created, it is possible to market ideas and behaviours associated with the Caring Campus Project online. To build a powerful online presence, regular posting is a must, either by blogging, posting articles, providing 
information and statistical data, giving notices of events, or posting online videos and linking into social media networks.

It is important to describe the successes of the Caring Campus Program, so posting achievements is important. It will give the audience the idea that the Caring Campus Program has momentum and is achieving what it set out to do. This means that the responsibility to maintain an active online presence must be a defined role in the organisation and the formal responsibility for this entrusted to an individual, who may then form a group to help. Posting success stories also keeps program volunteers enthusiastic about their role, as volunteers will want to be able to describe program accomplishments.

\section{Summary}

Planning for sustainable action may be the most challenging aspect of the Caring Campus Program's development. It doesn't happen automatically, it requires considerable thought and strategic planning from the leadership. This includes developing the program's structure, determining and acquiring financing, creating and retaining the people resources needed to operate the program, and ensuring that the program has ongoing presence and can keep the dialogue going. 


\section{References \& Resources}

\section{Module 1}

Health Canada (2008). Canadian Addiction Survey (CAS): A National Survey of Canadians' Use of Alcohol and Other Drugs - Focus on Gender. Ottawa.

National Defense and the Canadian Armed Forces (2016) The Military Mental Health Continuum Model. Ottawa, Ont. Retrieved from http://www.forces.gc.ca/en/cafcommunity-health-services-r2mr-deployment/mental-health-continuummodel.page

\section{Module 2}

National Defense and the Canadian Armed Forces (2016) The Military Mental Health Continuum Model. Ottawa, Ont. Retrieved from http://www.forces.gc.ca/en/cafcommunity-health-services-r2mr-deployment/mental-health-continuummodel.page

Stuart, H., Chen, S-P, Christie, R., Dobson, K., Kirsh, B., et al. (2014a). Opining Minds in Canada: Background and rationale. Canadian Journal of Psychiatry, 59, S8-S12.

Stuart, H., Chen, S-P, Christie, R., Dobson, K., Kirsh, B., et al. (2014b). Opining Minds in Canada: Targeting change. Canadian Journal of Psychiatry, 59, S13-S18.

\section{Module 3}

Ahlfeldt, S., Mehta, S., \& Sellnow, T. (2005). Measurement and analysis of student engagement in university classes where varying levels of PBL methods of instruction are in use. Higher Education Research \& Development, 24(1), 5-20.

Hansen, D. M., \& Larsen, R. W. (2007). Amplifiers of developmental and negative experiences in organized activities: Dosage, motivation, lead roles, and adult-youth ratios. Journal of Applied Developmental Psychology, 28, 360-374.

Holloway, J. H. (2002). Extracurricular activities and student motivation. Educational Leadership, 60(1), 80-81

Juvonen, J., Espinoza, G., \& Knifsend, C. (2012). The role of peer relationships in student academic and extracurricular engagement. InHandbook of research on student engagement (pp. 387-401). Springer US.

Man to Man. (2009). Fredericton Sexual Assault Crisis Centre.

White, A., Seims, A., \& Robertson, S. (2015) Proceedings of an expert symposium on the mental health and wellbeing of men and boys, November 6th, 2014, Leeds. 
London, UK: The Movember Foundation in association with Leeds Beckett University and the Men's Health Forum.

\section{Module 4}

Andreasen, A. R. (1994). Social marketing: Its definition and domain. Journal of Public Policy \& Marketing, 13, 108-114.

Burchell, K., Rettie, R., \& Patel, K. (2013). Marketing social norms: social marketing and the 'social norm approach'. Journal of Consumer Behaviour,12(1), 1-9.

Haines, M. P., Perkins, H. W., Rice, R. M., \& Barker, G. (2005). A guide to marketing social norms for health promotion in schools and communities. National Social Norms Resource Center. Retrieved from http://www.socialnormsresources.org/pdf/Guidebook.pdf

Miller, D. T., \& Prentice, D. A. (2016). Changing norms to change behavior. Annual review of psychology, 67, 339-361.

Previte, J., Russell-Bennett, R., \& Parkinson, J. (2015). Shaping safe drinking cultures: evoking positive emotion to promote moderate-drinking behaviour. International Journal of Consumer Studies, 39(1), 12-24.

Resource websites:

Social Norms National Research \& Resources: http://www.socialnormsresources.org/FAQ/questions.php

The 7-Step Montana Model on Social Norms Marketing: http://chsculture.org/wpcontent/uploads/2014/09/The-Toolbox.pdf

Social Norms Guidebook:

https://europeansocialnormsinstitute.files.wordpress.com/2014/05/social-normsuk-guidebook-june-2010.pdf

National Social Norms Center: http://socialnorms.org/for-practitioners/

The Social Norms Approach resources: http://www.alanberkowitz.com

\section{Module 5}

Corrigan, P., Michaels, P. J., Vega, E., Gause, M., Larson, J., Krzyzanowski, R., et al. (2014). Key ingredients to contact based stigma change: A cross-validation. Psychiatric Rehabilitation Journal, 37(1), 62-64. 
The Mental Health Commission of Canada's Opening Minds Initiative)

Suggested resources:

Visit the following websites for examples of personal stories offered as videoclips:

https://www.facebook.com/pg/ManUpMentalHealth/videos/?ref=page internal

http://theprosocialproject.ca/my-story 


\section{Appendix A1: The Substance Use Wellness Tool - Leaflet}

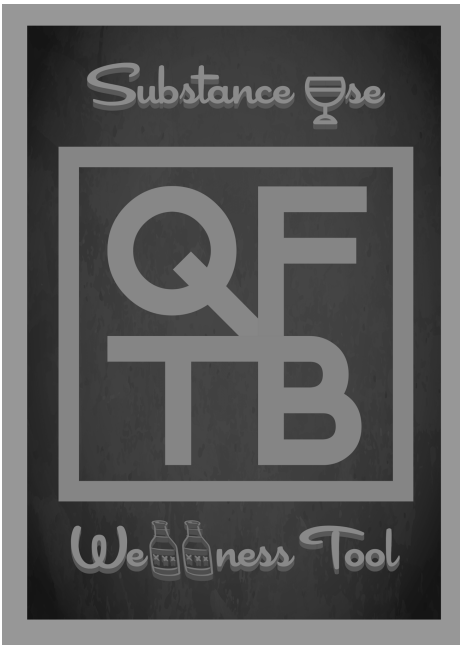

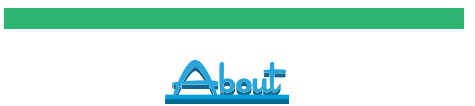

- Students often use substances to relieve stress, improve mood or enhance performace, creating a clear link between substance and mental health

- This wellness tool will help you

to identify your substance use patterns so that you can self-monitor their impact on yourself and others

- Place yourself on this continuum using the list of behaviours provided to determine how much substance use may be disrupting your life

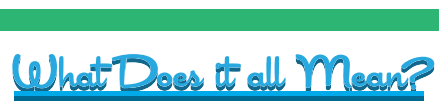

- Emphasis is on enabling you to take charge of your using patterns so that you can have control over their impact on you and not the other way around

- Colours on the continuum are oriented towards the impact of substance use and are not meant

to judge you or label that you have an "illness"

- Talk about substance use and its overall impact on your daily life, whether physically, mentally or socially

\begin{tabular}{|c|c|c|c|}
\hline & Alert & Consider Support & Seek Support \\
\hline Limited Use & Regular, but controlled use & Difficulties with control/excessive use & $\begin{array}{l}\text { Persistent difficulty with control of } \\
\text { use/excessive use }\end{array}$ \\
\hline Not used as a coping strategy & Sometimes used as a coping strategy & Regularly use as a coping strategy & Use as the main coping strategy \\
\hline $\begin{array}{l}\text { Rarely use in response to peer } \\
\text { pressure }\end{array}$ & $\begin{array}{l}\text { Sometimes use in response to } \\
\text { peer pressure }\end{array}$ & $\begin{array}{l}\text { Often use in response to peer } \\
\text { pressure }\end{array}$ & $\begin{array}{l}\text { Almost always use in response to peer } \\
\text { pressure }\end{array}$ \\
\hline Never use alone & Sometimes use alone & Regularly use alone & Almost always use alone \\
\hline $\begin{array}{l}\text { Most friendships and activities not } \\
\text { centred around substances }\end{array}$ & $\begin{array}{l}\text { Some friendships and activities } \\
\text { centred around substances }\end{array}$ & $\begin{array}{l}\text { Most friendships and activities } \\
\text { dominated by substances }\end{array}$ & $\begin{array}{l}\text { Almost all friendships and activities } \\
\text { dominated by substances }\end{array}$ \\
\hline Never use to get high & Sometimes use to get high & Often use to get high & Almost always use to get high \\
\hline Connections are not affected by use & $\begin{array}{l}\text { Connections are sometimes } \\
\text { affected /others express some } \\
\text { concerns about my use }\end{array}$ & $\begin{array}{l}\text { Connections are often affected/others } \\
\text { moderately concerned about my use }\end{array}$ & $\begin{array}{c}\text { Connections are almost always } \\
\text { affected/others seriously concerned } \\
\text { about my use }\end{array}$ \\
\hline Educational goals not affected & $\begin{array}{l}\text { Educational goals sometimes affected } \\
\text { by use/GPA not in jeopardy }\end{array}$ & $\begin{array}{l}\text { Educational goals often affected/GPA } \\
\text { starting to be jeopardized }\end{array}$ & $\begin{array}{c}\text { Educational goals seriously affected/ } \\
\text { GPA in jeopardy }\end{array}$ \\
\hline Physically well & Sometimes physically unwell & Often physically unwell & $\begin{array}{l}\text { Almost always physically unwell/ } \\
\text { well-being impacted }\end{array}$ \\
\hline Finances not impacted & Finances occasionally impacted & Finances impacted & Significant financial troubles \\
\hline $\begin{array}{l}\text { Don't engage in risky behaviours } \\
\text { that could harm self or others }\end{array}$ & $\begin{array}{l}\text { Sometimes engage in risky behaviours } \\
\text { that could harm self or others }\end{array}$ & $\begin{array}{l}\text { Often engage in risky behaviours that } \\
\text { may harm self or others }\end{array}$ & $\begin{array}{l}\text { Almost always engage in risky } \\
\text { behaviours that harm self or others }\end{array}$ \\
\hline
\end{tabular}
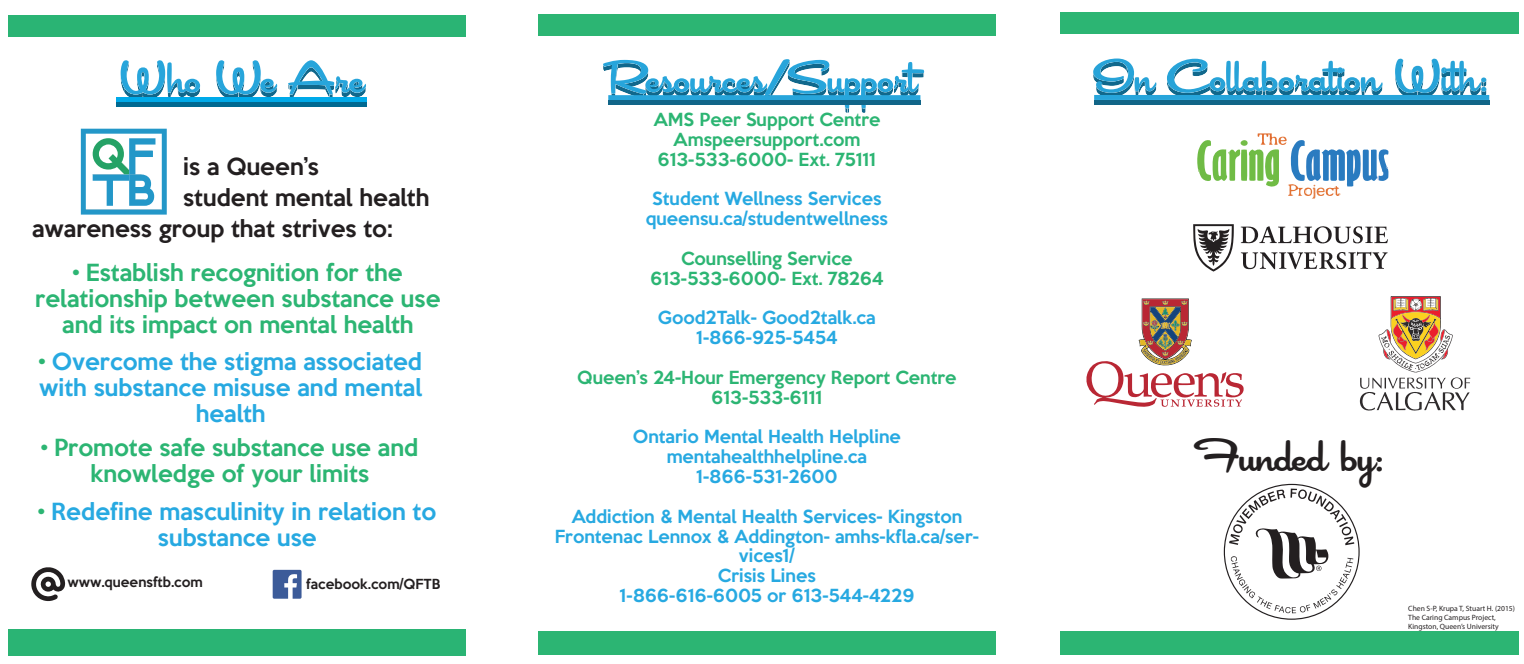


\section{Appendix A2: The Substance Use Wellness Tool - Information package}

\section{Substance Use Wellness Tool Information Package}

Our Aim:

The Caring Campus Project is a Movember funded project that seeks to prevent substance misuse and related mental health issues among first year male students on post-secondary campuses. The project consists of an interdisciplinary team of professors, post-doctoral students and research associates at three Canadian universities: Queen's University, Dalhousie University and Calgary University. The Substance Use Wellness Tool was developed as a guiding framework to address students' substance use patterns and their related effects on mental health. Our research team intends to broadly disseminate this tool so that identified stakeholders can use it as a resource. For students, this tool can serve as a self-help resource to demonstrate the relationship between substance use and mental health. In addition, clinicians and other stakeholders can use this as a tool to identify substance use issues in clients, a client wellness tool, or as a guiding framework for educational workshops.

\section{Description}

The Substance Use Wellness Tool is intended to raise awareness and identify substance use issues among students on university campuses. The idea of a visual continuum was based on the widely disseminated Mental Health Continuum that is used in educational programs by the Department of National Defense. The Substance Use Wellness Tool was developed to help normalize and de-stigmatize substance misuse issues, increase the dialogue and promote help-seeking behaviours among students. The model approaches individuals in a holistic fashion, as it seeks to identify the physical, psychological and social repercussions of substance use. In using this tool, students can self-monitor the impact of their substance use patterns on themselves and their peers. As awareness increases, it will enable students to take control of their use so that they can experience an optimization in health and well being.

\section{What does It Mean?}

The colours on the continuum are indicators of the level of concern that could occur due to substance use. For example, the category green has several behavioral indicators that would indicate healthy use or relatively no disruptions to daily life due to substance use. Yellow indicates caution, orange indicates alert and red indicates alarm.

These categories enable people to talk about substance use in language that is not stigmatizing and communicate what is occurring in their everyday life as a result of substance use. The arrow illustrates that students' usage patterns can vary across the dimensions of the continuum and that they can take steps to move back toward healthier patterns.

\section{What does it Not Mean}

The Substance Use Wellness Tool is not intended to diagnose nor categorize, label or judge any individual as having a substance abuse disorder. It is a tool that can be used to support individuals in identifying and overcoming difficulties that they may be experiencing due to substance use. 


\section{How to Use}

To use the Substance Use Wellness Tool go through the different behavioral domains in each category to identify which aspects of daily life are being impacted by substance use. On an individual level, students may use the continuum as a reference tool to identify if any aspects of their own or their peers' lives are being disrupted due to substance use. During this process of identification, students may reflect on their usage patterns and experience a heightened level of awareness that may instigate change.

The continuum may also be provided to individuals offering support or mentorship to the student population. Student peer support staff and campus residence dons are just a few of those in the position to offer support and mentorship. These individuals can be educated and trained on how to use the Substance Use Wellness Tool in order to use it as a reference point should students have issues related to substance use. In addition, peer support staff and dons receive training in mental health but may not be looking for substance use issues that may be underlying mental health concerns. Providing a brief description of the Tool during peer support and residence don training may make these staff members attuned to substance use issues that students may be facing.

\section{Development}

The categories part of the Substance Use Wellness Tool were created based on focus groups that included university students and parents of students in order to gain an understanding of the post-secondary experience and culture related to substance use. Based on the feedback that was obtained, 13 domains were identified that may be impacted by substance use. These domains would then serve as the basis for the behavioral indicators outlined.

\section{Validation}

The Caring Campus Project team conducted a study measuring the Substance Use Wellness Tool with a criterion measure, the Alcohol Use Disorders Identification Test, in order to assess whether the continuum would be a valid screening tool to identify students' substance use issues. The finding suggested that the continuum could potentially be used as a screening tool to identify substance use issues. 


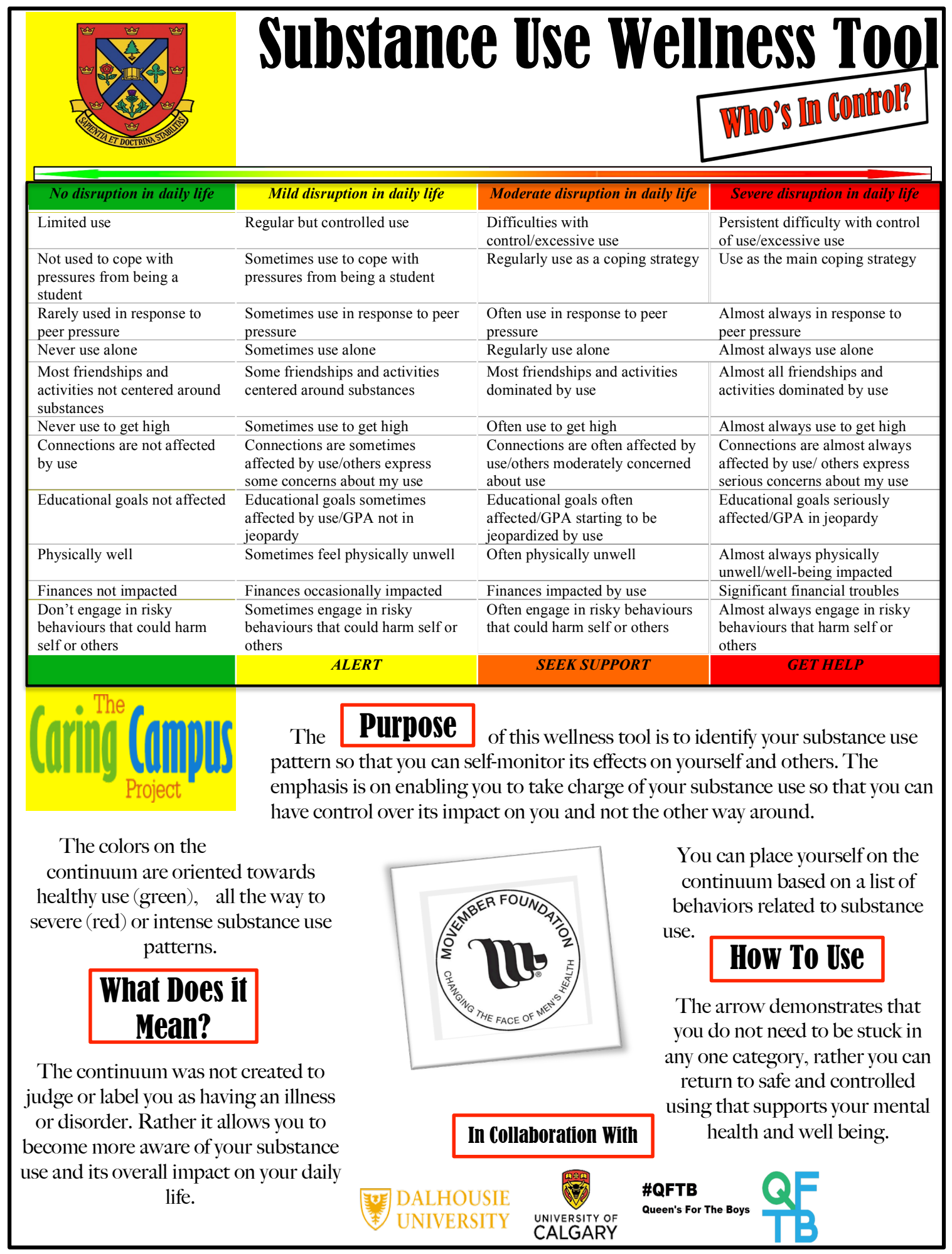




\section{Appendix A3: PowerPoint slides from one workshop related to the Substance Use Wellness Tool}

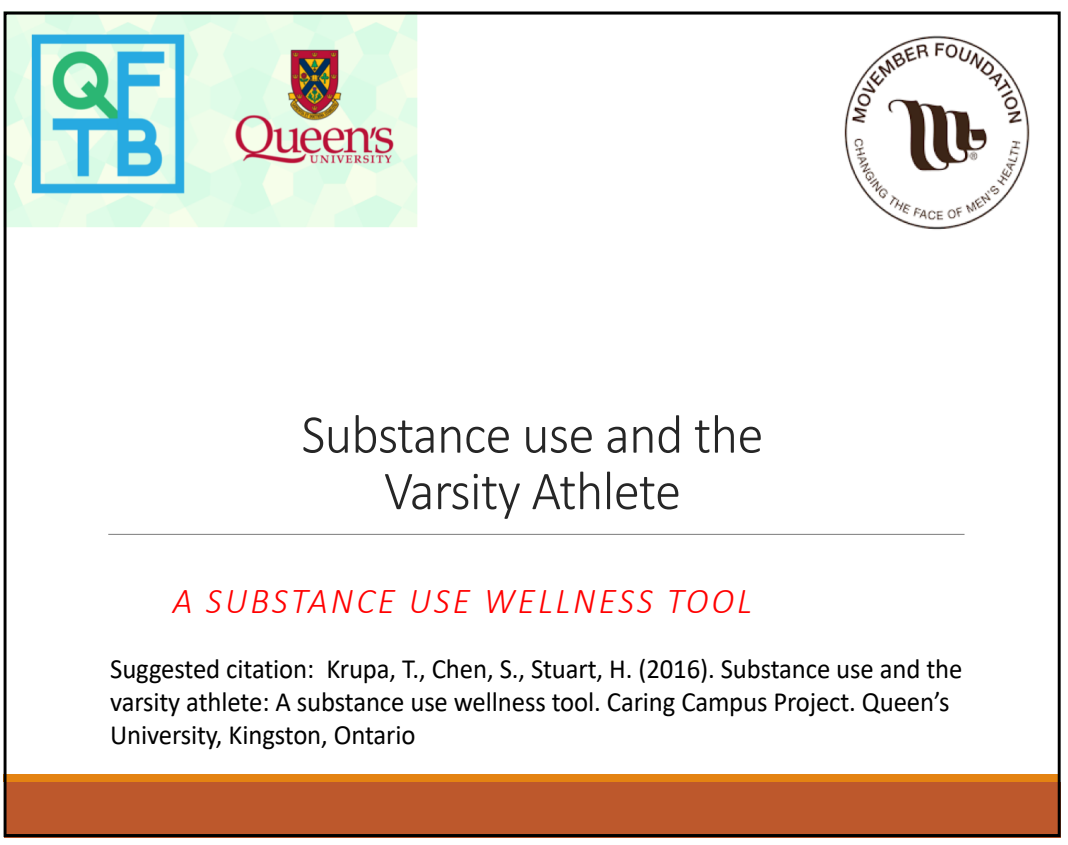

\section{The issue}

Substance misuse issues are prevalent among university students

Pressures of varsity athletics contribute to health and well-being related to substance use 


\title{
Particular pressures of varsity athletics
}

\author{
Pressures to: \\ Athletic Performance \\ Fit in \\ Cope with demands of competition \\ Cope with personal loss/injury related to athletics \\ Maintain academic standards
}

All pressures that have been linked to substance use and associated mental health issues among post-secondary students

\section{A substance use wellness tool for university students}

The goal?

Supporting self-awareness

Recognizing substance use issues in others

Destigmatizing substance use

Increasing dialogue

Taking control

Seeking support 


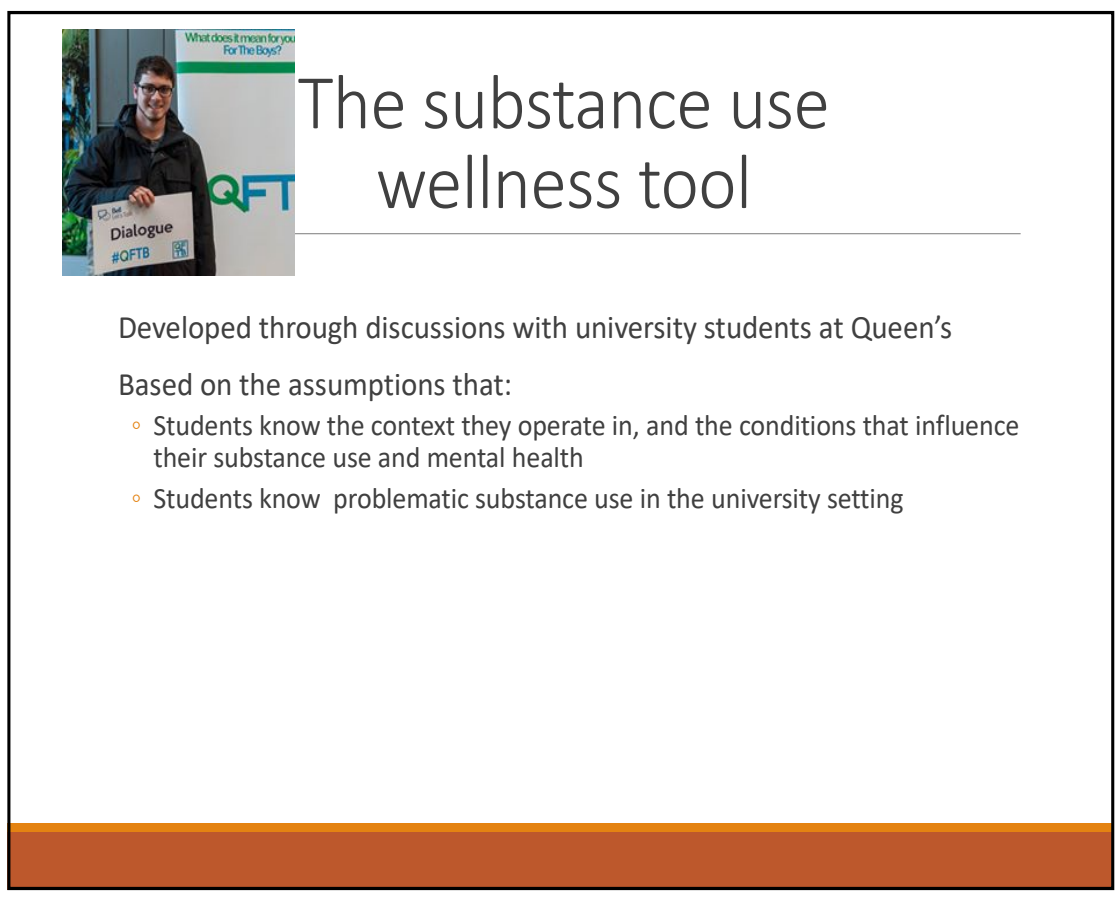

\section{How the tool works}

Modelled on the mental health continuum from the Department of Defense

A tool for reflection on substance use behaviors - personal or peers

Across a range of campus-life conditions and contexts associated with substance use

For example:

Frequency and intensity of substance use

Social conditions surrounding substance use

Social, physical, financial, risk consequences associated with use 


\section{Using the tool}

Colours as indicators of potential for concern

- Green-Wellness in the area of substance use

- Yellow-Caution, emphasis on recognition of use

- Orange- Alert, make wellness a priority

- Red- Alarm, seek supports

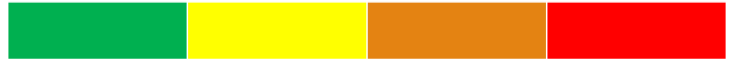

Think about "pattern" of use - three or four indicators in the orange suggest need for attention

\section{Using the tool for self- reflection}

1.Take some time now to review the substance use wellness tool and to reflect on:

-Your own substance use patterns

-The substance use patterns of friends you have been concerned about

2. In pairs/small groups discuss the usefulness of the tool. Consider:

- Is it a useful way of thinking about substance use? 


\section{Using the tool to consider shifts in substance use patterns}

For example:

SEEING RED

Using the tool a Queen's varsity athlete sees a pattern of "red" behaviours:

- Almost always uses substances to cope with stress

Almost always uses alcohol in response to peer pressure

All social/recreational activities with friends involve alcohol use

S/he would like to change this "pattern" to see these concerns move to "orange or yellow".

What might he/she do to make this shift?

\section{The substance use tool and the varsity athlete}

The tool was designed for the university student population in general

Are there some areas that are most relevant to student athletes?

Are there some areas that should be added?

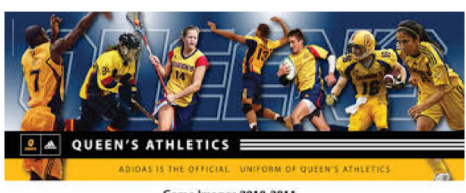

Game Images 2010-2011 


\section{Appendix B: The Summit Approach - Example of Job posting to hire student leaders}
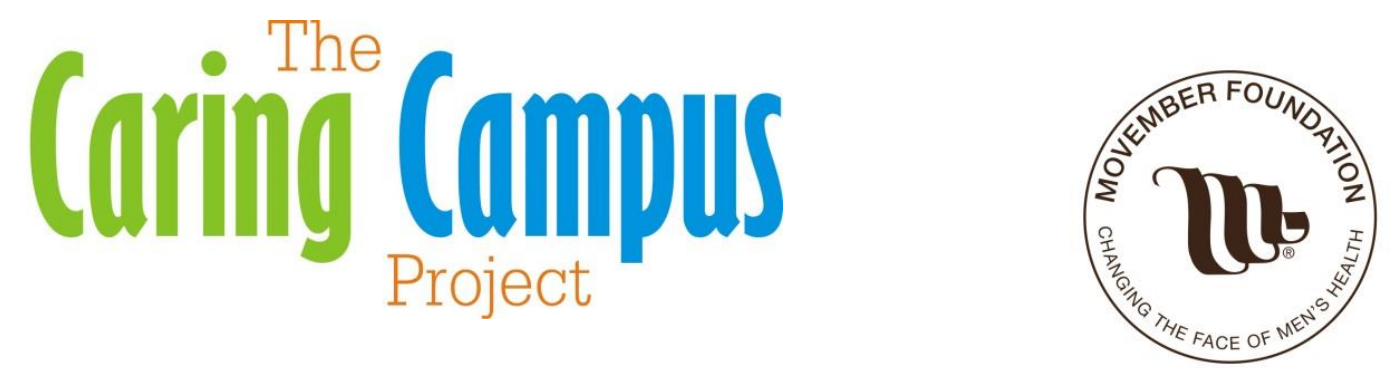

\section{Now Hiring! Male Student Leaders for The Caring Campus Project}

\section{The Caring Campus Project - An Overview}

Movember Canada cares about men's mental health. Researchers at the University of Calgary were recently awarded a grant to mount a mental wellness program targeting first year freshmen. The goals are to reduce risks associated with mental ill health and substance misuse and create a campus culture supportive of mental health and substance use patterns that promote health and well-being.

Males are particularly vulnerable to substance misuse linked to mental ill health during their first year at university. University freshmen experience stressors during their transition from family life to independence, and may use substances to relieve stress, anxiety, or depression. In addition, substance misuse that occurs in first year may set a pattern for future use patterns. This may place them at high risk for mental health problems, mental illnesses, suicide, and substance abuse disorders.

The overall aim of the Caring Campus project is to help male freshmen learn about mental wellness and safe substance use patterns; correct misperceptions about substance use norms; and promote student - driven and led activities to raise awareness of the importance of early identification and intervention and create a culture that promotes mental health and well-being. Opportunities for active engagement and dialogue will be a central component.

In addition, the University of Calgary is working in partnership with Alberta Health Services to utilize their newly developed guide, Reducing High Risk Drinking on Alberta Campuses: Alberta Students Taking Responsibility Together, in how we tackle some of the challenges associated with this project. 


\section{Time Commitment and Approximate Project Schedule}

We are looking for student leaders who are able to commit to being a part of this project from February 2015 - April 2016 (15 months).

February 2015 - April 2015

- You are required to attend a full day summit at the end of February in order to learn more about the project, talk about ideas, and make plans for what you want to accomplish

- Following the summit there will be monthly meetings to work on building leadership and project management skills and to maintain a dialogue about the types of projects you are interested in initiating.

Summer

○ We will not have meetings during the summer; however you will need to be available for the last two weeks in August in order to be ready for orientation week and for the kickoff of Caring Campus in September 2015.

September 2015 - April 2015

- Run awesome initiatives!

- Meet once per month as a full group to discuss progress .

- Meet regularly in smaller working groups to organize and implement activities

* Male identified student

\section{Required Qualifications}

* First or second year student

* Commitment to being a student at the University until the end of April 2016

* A commitment and interest in substance use, mental health, and health programming

* Interest in serving in a leadership role

\section{Compensation}

* There is a stipend attached to this position for the amount of $\$ 2000$. This will be paid out in $4 \$ 500$ increments throughout the execution of the project.

\section{How to Apply}

Please submit a cover letter and resume to ccampus@ucalgary.ca by January 23rd. 


\section{Appendix C. Contact-based Education - Speaker Training Package}

*The Caring Campus Speaker Traing Package was modified from:

- Sharing Your Personal Story: Speaker Toolkit. Mental Health Commission of Canada: http://www.mentalhealthcommission.ca/sites/default/files/MHCC\%25252 0Headstrong\%252520Speaker\%252520Toolkit 0.pdf

- Speaker Training Tool. Talking About Mental Illness (TAMI) Durham: http://tamidurham.ca

\section{The Caring Campus Project Speaker Training Guide}

\section{Your role as a speaker}

The objectives of the contact-based education involve improving:

1. students' awareness about substance use and mental health issues

2. students' stereotypical attitudes toward people with substance use issues

3. students' social acceptance of people with substance use issues

4. students' sense of social responsibility for promoting an inclusive campus environment.

5. the campus cultural environment so that it becomes more inclusive of people with substance use or mental health issues.

Your participation as a speaker is a key for change. As a speaker your role is to:

- Attend the speaker training to understand the Caring Campus Project and acquire presentation skills

- Share your personal story and commit to educating university students about substance use issues

- Develop a 10-15 minute speech detailing your personal story

- Present this speech to a group of 15 or more student leaders in the Summit 
- Answer students' questions about your experiences in a positive manner

\section{Four steps to develop your personal story}

\section{Step One - Develop your main ideas}

Follow these questions to guide your thinking about your story

- Your positive life experiences before starting use of substance: (talents, education, work, hobbies, relationships, etc.)

- What are your warning signs of getting trouble with substance use?

- What factors do you think were associated with your substance use problems?

Queen's culture about substance use:

- What effect did your substance use problems have on your university life? (academic, work, relationships, family, activity participation, attitude toward life, etc.)

- What were your feelings during the most difficult time?

- How did your family and friends respond to your substance use problems? 
- How did you go through the difficult situation? What was helpful in supporting you dealing with the problems?

- How are you now? What do you do now?

- What are your future goals and expectations: (work, education, relationships, activity participation, advocacy, etc.)

- What positive life experiences happened while you were resolving your substance use problems? What have you learned?

- What advice would you give to other university students?

\section{Step Two - Think about your core messages}

During the presentation, we want to include the following core messages. These are powerful and can change audiences' perceptions about substance use. When you write your story in the next section, try to incorporate these core messages into your story.

- Experience in the first year

- Coping strategies

- Getting help

- Hope

- Stigma and common misperceptions related to substance use and mental health

- The impact of campus culture 
Based on the ideas you have developed in Step One and the core messages you learned in Step Two, follow the guideline below to complete your story writing. You will prepare a 10-15 minute story. The story includes three major parts: the opining, the body of the story, and the closing.

- A strong opening tells your audience what you are going to talk about. You can begin with something attractive to catch the attention of the audience to CONNECT_with something interesting.

- It's best to organize the body of your story CHRONOLOGICALLY (from past to present). Try to include all of the main themes.

- Summarizing your KEY MESSAGES makes a strong closing. We want to emphasize the importance of changing campus culture.

\section{The story writing outlines}

Here is a story outline to get you going.

\section{Opening:}

I am

I want to share my experience of substance use because ...

When I was the first-year student, I ...

\section{Body of the story:}

Start drinking (or using drugs) and warning signs of getting trouble

How life was affected 
My feelings/struggle (experience stigma?)

Events that sent you for help

Getting help (how, who, when, where, and what)

Learning to manage the problems and coping strategies

Now I am

Plans for the future

My advice to you

\section{Closing:}

Summary the take-home messages 
Step Four - Review, edit, and practice your story

Developing your story can take many revisions. Do not worry about how it looks for the first draft. Just get your thoughts organized on paper.

You can read through your draft, correct any errors, add new ideas, change your expression, or rearrange the sequence. You will find that you will make many revisions during the course of practicing your story.

In the first couple of practice sessions, read your story out loud to yourself to see whether it rolls off your tongue. Change anything that seems to be difficult to say or anything that sticks. Once you have done this, you are ready to present your story.

\section{Core Presentation Skills}

We list some important presentation skills that can help you deliver your message with impact.

- Always look at your audience: This will help you make a good connection with the audience and keep them engaged. Try to hold eye contact with someone in the audience for a short while (3-5 seconds) then move to another person.

- Speak loudly: Speak to the person in the back of the room. That way everyone will hear you.

- Use body language: Practice using hand gestures to emphasize important points. Remember that you can move around the room. Make sure you don't fidget with anything while you are talking.

- Create a professional image: Looking professional is a matter of respect. It tells the audiences you respect yourself and you respect them. Try to create a professional image through your dress and demeanor. Remember, you want to present a positive visual image and act as a role model for recovery!

- Connection: Try to connect with your audience. Think back to your own experience as a freshman. What was it like for you when you were the first-year student? Provide your audience with experiences that they can relate to. This connection will help them engage in your presentation. Don't forget to smile!

- Prepare and plan for what you want to say: Organize your thoughts and remember your outline and key contents. If you practice your talk enough times, this will come easily. 
- Pace yourself: Change your volume, avoid speaking in a monotone, avoid talking too fast (even if you are nervous), remember to use pauses to emphasize your points, and remember to breath evenly.

- Summarize a clear take-home message: Make sure that you have a clear statement or message that you want students to take home from your presentation. Be sure that this message is one that is positive and tells students how they can help their peers.

- Practice: Practice makes perfect. At a minimum, you should practice your presentation in front of others 9 or 10 times before you present to students. If you are new to public speaking, you may want to add additional rehearsals in front of others before you feel fully comfortable with your story.

- Be open, confident, and genuine: Student's will be eager to hear what you have to say. If you are nervous, don't hesitate to tell the students. They will likely empathize with you. Remind them that it is difficult to stand in front of an audience and tell people about personal experiences with substance use issues.

- Engage with students: Students would rather have a conversation with you, so make sure you leave time for questions. During your presentation, you can engage them by asking rhetorical questions or by asking them to imagine how something feels. 